XELI.

\title{
DIGEST OF AMERICAN AND ENGLISH OTOLOGIC LITERATURE FOR THE YEAR 1918.
}

\author{
By OTro M. Rotr, M. D., \\ Spokane, W.ishington. \\ I.-HEARING; Trists.
}

1. Brownfleld, R. R.-Detection of Pretended Loss of Hearing with Special Reference to Unilateral Deafness. Jour. A. M. As8., Chlcago, 1918, LXX, 597.

2. Callahan, J. F--Hearing Test to Detect Malingering. Boston M. \& S. J., 1918, CLXXIX, 236.

3. Callahan, J. F.-Hearing Test with Voice to Detect MallngerIng. Boston M. \& S. J., 1918, CLXXIX, 423.

4. Gradenigo, D.-The Unit of Sound. StePanlni's Phonometer with Ball and Sounder. J. Laryngol., Lond., 1918, XXXIII, 197.

5. Kerrison, P, D. - The Tests for Malingering in Defective Heartng. Laryngoscope, St. Louis, 1918, XXVIII, 662.

6. Mollison, W. M.-A Note on Schultze's Monochord. J. Laryagol., Lond., 1918, XXXIII, 365.

7. Prenn, Joseph.-Hearing Test Apparatus Boston M. \& S. J., 1918. CLXXVIII, 896.

8. Teal, Frederick F.-A New Ear Test for Mallngering. Laryngoscope, St. Louls, 1918, XXVIII, 615.

Brownfield offers a device for detecting malingering, in which device batteries and make-and-break contacts are entirely dispensed with. The ordinary 110 volt alternating commercial lighting current is used. The variable current is produced by a potentiometer, and is variable from an absolute zero to maximum. No vibrating iron is used, and the maximum strength of current employed is dependent on no factor except the ratio of the electrical resistances employed. The sound producer is similar to a telephone receiver except in one very important respect-the fore is of soft iron and is not magnetized. This results in eliminating the variability due to demagnetization and doubles the pitch, so that the ordinary 60 cycle current produces 240 vibrations per second-about equal to the average tone used in conversation. 
The sound producer is provided with three lugs to hold it away from the ear, so that the sound will be transmitted salely by air conduction. By simply turning the indicator from 100 to zero, one can cause the sound to increase from the point at which it is just perceptible to one of normal hearing, the threshold of audition, or 100 per cent acuity, to a degree of intensity at which failure to perceive it indicates that the subject has no practical hearing. In addition to the variable receiver, there is a supplementary one that always operates at maximum intensity, irrespective of the loudness of the other.

In the usual test for the acuity of hearing, only the variable receiver is used. As the subject holds this to the ear, the pointer is gradually moved from zero to the 100 point. As the intensity of the sound gradually increases, he is told to indicate the point at which he is no longer able to perceive it. This point is noted, and the movement of the pointer continued still farther. The direction is then reversed and the subject directed to indicate the point at which the sound is again heard. After one or two trials, the various readings will be found to harmonize quite closely unless one has a case of malingering, which may be readily detected by inconsistency of the readings. It is hardly necessary to remark that the electric control has a distinct advantage over the watch and whisper tests, as the malingerer is totally unable to guess what reply would be expected from one of defective hearing. The only precaution necessary is to place the instrument back of him. A small push button is provided, which may be used to disconnect the receiver, in case the subject is uncertain whether he hears the vibrations or is confusing it with tinnitus.

The application of the instrument consists in having the patient hold the constantly loud receiver over the alleged deaf ear, and the variable receiver over the other. Starting with the pointer at 100 (minimum sound), it is gradually moved toward zero and the subject directed to state when he first hears the sound in his good ear. If he really suffers complete loss of hearing in one ear, as claimed, the presence of the loud receiver will not disturb him or interfere with the perception of sound by the other ear; in fact, it might just as well be disconnected. Under this presumption he would have 
no difficulty in clearly detecting the sound in the other ear, and we would soon have a proper index of its acuity. If, however, he is merely pretending and actually has a very fair degree of hearing in both ears, it would be absolutely impossible for him to identify any sound whatever in his good ear, to which the variable receiver is applied, until a point on the scale is reached that would normally indicate very defective or almost no hearing for the good ear.

The very nature of the test facilitates the detection of fraud, because the better he can hear in the alleged defective ear the less will he hear in the other-a condition just the opposite of what he might expect; and so when he makes his usual negative reply he is for once telling the truth and trapping himself.

Callahar's test to detect malingering is based on the fact that tuning forks vibrating with the same pitch and loudness one inch from each ear are heard in each, but that if the fork at the left ear is removed to a point three inches from the ear, this sound is lost and only the fork remaining at one inch from the right ear is heard. If now the one at the right ear is removed six inches from the ear, it will no longer be heard; but the left one, formerly not heard, will again become audible. Similar results were obtained if the fork was placed against a rubber tubing.

For this test the author uses a seven foot length of rubber tubing, hole 3/16 inch, diameter of wall of tubing $6 / 16$ inch, to either end of which is attached an aluminum funnel. The funnels are held to the ears and about one inch away from them by a simple attachment on the headrest of the examining chair, which allows of adjusting them to cover the ears without touching the patient.

The $256 \mathrm{Cl}$ fork is heard by the normal ear, when placed against the tubing at any point up to $71 / 2$ feet. With a larger sized tubing the same fork is heard as far away as 30 feet.

The application and results in an individual with two normal ears are as follows: The seven foot tube is connected with one funnel, the latter being placed about one inch from the right ear. The tuning fork vibrating is applied to the tube about six inches from the ear and moved along the tube away from the ear until it is no longer heard. This will usually be about seven to seven and one-half feet. The tube is now 
disconnected from the right funnel and attached to the left, and the same procedure followed. If normal, the left ear will also hear the sound of the fork transmitted along the tube up to seven feet or more from the ear. Now the tube is attached to both funnels. The vibrating fork is applied to the tube one foot from the right ear and moved along the tube away from the right ear and toward the left ear. It will be heard only in the right ear until it reaches a point about three to three and one-half feet from the right ear, at which point it will be heard also in the left ear, and will continue to he heard in both ears for a distance of about four inches in the middle of our 7 foot tube. It is this space of about 4 to 6 inches in the middle of the tube that is called "the neutral space." The sound in this neutral space almost imperceptibly disappears from one ear to appear in the other, and in this space there is some doubt in the patient's mind in which ear he hears the fork: As the neutral space is passed through, the sound becomes perceptible in the left ear and is not heard in the right. It is to be noted well that whereas the right ear heard the tuning fork up to 7 feet in the first part of the test. it now loses the sound of it along the same tubing at about $3 \mathrm{r} / 2$ feet, because in this second instance the other end of the tubing goes to the left ear, and as the tuning fork passes from the right half of the tubing through the neutral space to the left half of the tubing, the sound is heard in the left ear alone. The detection of feigning now becomes practicable if it takes the form of misstatements concerning the hearing in one ear.

The detection of malingering is illustrated by the following case in which total deafness in the right ear was claimed: With the long "one ear" tube connected with his left ear it was found on -several tests that he heard the fork up to $7 \mathrm{1} / 2$. feet from the ear. With the same tubing connected with the funnel for the right ear, he persistently held that he did not hear it even at 4 inches from the ear. The tube was then connected with both funnels and the tuning fork started at the left-good-ear. He admitted hearing the sound in the left ear until we reached a point forty inches from the left ear, when he said that he could not hear it. From this point onward up to 4 inches from his right-bad-ear, he claimed not to hear the sound. The tuning fork was then placed over 
the coupling in the tube-this point being 14 inches from his right ear and 70 inches from his left. He said he did not hear it. The coupling was taken apart and the fork again touched to the tube at the same place where he had just said he heard nothing, viz. : 70 inches from the left ear on the end that went to the left ear, and he said he heard it in his left ear. He was caught, for if his right ear had been deaf, he would have heard the sound in his left ear at this point and at every other point up to 84 inches from his left ear while the tubing was still connected with both funnels. He reported not hearing the sound to the right of the neutral space because he was determined to give a negative answer whenever he heard the sound in his right ear.

Callahan also uses the voice to detect malingering with the same apparatus used for tuning forks, with the exception that as a mouthpiece an ether cone is used and this connected to the two pieces of tubing.

Gradenigo describes a modification of Stefanini's phonometer, an instrument for rendering a standard sound unit for testing the hearing.

Kerrison describes the tests for malingering in defective hearing which he has employed in connection with the examination of drafted men. 'The tests, upon the continued results of which he bases his conclusions are: (1) Weber's test; (2) the loud conversational voice test; $(3)$ the binaural stethoscope test; (4) tests eliciting incongruous variations in response; (5) the noise apparatus-reading test (Lombard's test).

Mollison describes the monochord and endeavors to establish its claims over the Edelmann-Galton whistle, in determining the upper tone limit of the ear.

Advantages are:

1. It is easily standardized.

2. It is simple to use.

3. By placing the support of the wire on the mastoid process the upper tone limit through the bone can be tested.

Prenn's hearing test apparatus consists of two rubber tubings, one to each ear, and the other ends connected with a funnel through which the whispered voice or tuning fork vibrations are made to pass. This is the same in principle as that described by Callahan. 
Teal proposes a new ear test for malingering, in cases of unilateral catarrhal deafness. The patient is blindfolded and the air conduction tested and is found to be negative. The Weber test is then used and usually (though reluctantly) he hears the fork in the deaf ear. Bone conduction over the mastoid is next tested and again he admits hearing the fork. $\mathrm{He}$ is then commended for his answers and assured that he answered as he should. The last and real test is now used. After saying that the last test (bone conduction) is to be repeated, the examiner places a nonvibrating fork (or lead pencil) over the mastoid and at the same time brings a vibrating fork close to the auricle. If the patient is malingering, he will answer that he hears the fork (thinking that he hears through the bone as before) and the fact of a normal path of air conduction is established. If he is really deaf he will, of course, not hear the vibrating fork.

A Hartmann " $\mathrm{C}$ " fork is used.

\section{II.-Vestibular Tests.}

1. Carpenter, E. R.-Value of the Neuro-Otologic Testa in the Army from a Diagnostic Standpoint. Jour. Am. M. Ass., Chicago, 1918, LXXI, 899.

2. Culbertson, L. R. -What Is the Cause of Defective Orientation or Equillbration? Ann. Otol., Rhinol. \& Laryngol., St. Louis, 1918, XXVII, 187.

3. Fisher, Lewla.-The Method of Analyols of the Barany Test in Pathologic Cases. Laryngoscope, St. 'Louis, 1918, XXVIII, 724.

4. Fysher, Lewis, and Lyman, H. W.-The Ear In "Stunt" Flying. Jour. Am. M. Ass., Chicago, 1918, LXXI, 1977.

5. Graef, Chas.-Vertigo. N. York M. J., 1918, CVII, 241.

6. Graef, Chas. - Bome Points of Interest in Tests of Labyrinthine Function. Laryngoscope, St. Lould, 1918, XXVIII, 811.

7. Hastings, H.-Reactions of the Normal Labyrinth. Recent Experience in the U. S. Aviation Examination. Ann. Otol., Rhinol. \& Laryngol., St. Louls, 1918, XXVII, 481.

8. Heitger, J. D.-The Appllcation and Interpretation of the Newer

Far Tests. J. Indiana M. Ass., Fort Wayne, 1918, XI, 135.

9. Jones, I. H. Value of Routine Examination of the Labyrinth. N. York M. J., 1918, XVIII, 167.

10. Ibid.-The Value of Ear Examination to the Neurologist. Ann. Otol., Rhinol. and Laryngol., St. Loula, 1918, XXVII, 881.

11. Ibid.-An Attempt at Simpliflcation of the Physlology of the Vestlbular Labyrinth. Laryngoscope, 8t. Louis, 1918, XXVIII, 472.

12. Lemere, H. B.-Oculomotor Reaction to Labyrinth Stimulation.

Jour. Am. M. Ass., Chlcago, 1918, LXXI, 901.

13. Lewis, E. R.-Influence of Altitude on the Hearing and the 
Motion Sensing Apparatus of the Ear. Jour. Am. M. Ass., Chlcago, 1918, LXXI, 1398.

14. Parsons, R. P., and Segar, L. H.-Barany Chair Tests and FlyIng Abllity. Jour. Am, M. Ass., Chicago, 1918, LXX, 1064.

15. Robertson, Chas. M. - Examlnation of Men Entering the Avlation Service. Jour. Am. M. Ass, Chlcago, 1918, LXXI, 813.

16. Scruton, W. A.-Eramination of Applicants for Aviation Service. U. S. Army. Disqualfying Factors in 1,500 Cases. Some Observations of Past-Pointing After Rotation. Ann. Otol., Rhinol. \& Laryngol., St. Louis, 1918, XXVII, 528.

17. Stimson, G. W.-The Static Iabyrinth. N. York M. J., 1918, CVII, 639.

18. Swan, C. A., and Lake, R.-The Results of a Series of Investigations Based on Framination of 110 Individuals, with Regard to the Time of Commencement and Duration of Nystagmus in the Caloric Test. J. Laryngol., Lond., 1918, XXXIII, 118.

Carpenter illustrates with a case report the value of the vestibular tests in making the diagnosis of multiple sclerosis of the cerebellar type, inasmuch as in this instance it involved chiefly the region open to examination by the Bárány tests. The author quite naturally concludes:

1. A more general use of the tests is indicated when dizziness is encountered.

2. A closer cooperation of the otologist with the neurologist is necessary in this work.

Culbertson advances the hypothesis that the labyrinth when not plumb with the vertical or horizontal plane of the body or the horizon might cause defective orientation or equilibration.

Fisher discusses the method of analyzing the Bárány tests, in order to determine (1) whether the lesion is functional or organic ; (2) if organic, whether the lesion is central or peripheral; (3) if central, where the lesion is located.

A functional condition may be suspected only if all responses are normal. A definite impairment of even one response points to an organic lesion.

As to differentiating between a central and peripheral lesion, the. following principles are important:

1. In a peripheral lesion all the responses are impaired, and conversely the presence of any one normal response to stimulation indicates a normal labyrinth and eighth nerve.

2. A spontaneous nystagmus in the vertical plane either upward or downward indicates a central lesion. 
3. If stimulation produces a "perverted" or an "inverse" nystagmus, then again the lesion is central.

As to the subject of localization of a central lesion, the author lays stress on the importance of visualizing the various pathways constituting the vestibular apparatus, and as an aid presents ten diagrams, which should be carefully studied and mastered.

The author then goes on to state certain hypothetical findings, showing on the charts where the lesions should be in order to produce the various findings presented.

Fisher and Lyman have made a study of the ear in stunt flying by reproducing the effects of stunt flying by whirling the aviator in a laboratory device.

The vertigo effects of ear stimulation learned in the air are noted:

i. There are three cardinal planes of vertigo: horizontal, frontal and sagittal.

2. A sense of being turned in a horizontal plane-horizontal vertigo-is less disturbing than a sense of being whirled in a vertical plane-vertical vertigo. Each semicircular canal, if stimulated, produces a vertigo in its own plane.

3. When a disturbing or disabling vertigo is indicated in the vertical canals, the effects can be greatly ameliorated by bringing the vertical canals in a horizontal plane, by bringing the head forward.

4. All types of vertigo are made less and less disturbing by continual repetition.

The practical application of the vertigo study to stunt flying is then discussed, showing what positions of the head after certain stunts render the vertigo less disturbing.

Graef discusses the subject of vertigo and offers the following summary:

1. The most frequent cause of vertigo is some fault in the internal ear, especially progressive degenerative disease.

2. In a case of dizziness, if labyrinthine tests are normal in vertigo and nystagmus, there is no fault here, and the vertigo is due to something irritating the static apparatus.

3. If vertigo alone or nystagmus alone is produced by the tests, the fault is outside the labyrinth itself. 
4. If tests show no reaction in vertigo or nystagmus, the fault lies in the labyrinth or in the eighth nerve.

5. Hemorrhage into the labyrinth is a rare condition. Emboli lodging in the labyrinthine blood stream are a cause of Menière's syndrome, as seen in caisson workers.

6. The eye is next in importance to the internal ear as a source of vertigo and should receive full attention after the labyrinthine condition has been tested.

7. Aside from paralysis a common fault in the ocular muscles is weakness of a superior rectus, with imbalance-hyperphoria. Vertigo on looking upward is therefore frequently met with. Even when lacking a frank fault-hyperphorıthe elevators of the eyeballs are the least able to do their work and suffer most through exhaustion by the efforts required of them.

Graef discusses (1) the physiologic basis of the phenomena from the vestibular tests, and (2) evidences of damage to one or both static labyrinths, together with points in the differential diagnosis between labyrinthine and intracranial disease; (3) evidences of intracranial disease found by labyrinth tests.

Hastings has studied the reactions of the normal labyrinth and has made the following observations in testing over 800 applicants for the U. S. Aviation Service:

1. As to spontaneous nystagmus, it was not once found.

2. As to after-nystagmus from turning, the average duration in 282 applicants was 23.49 seconds a fter right rotation and 24.17 seconds after left rotation (15 to 35 being the extremes in about 99 per cent of the applicants examined).

The average difference in seconds in after-nystagmus from right rotation and left rotation was $2 \frac{1}{8}$ seconds, in 200 cases studied. In only two of the 200 cases was there a difference of 10 seconds, and in no case more than 10 seconds between the right and left rotation after-nystagmus.

3. Spontaneous past-pointing was not found.

4. The past-pointing reaction after turning was elicited according to rule in about 90 per cent of those examined. The average namber of times of past-pointing in 283 cases was as follows: Right arm, 2.22; left arm, 1.91 (after right turning). Right arm, 2.18; left arm, 1.96 (after left turning). Of 700 applicants, 47 cross-pointed with one or both arms on turning 
for past-pointing, as follows: On right turning, 5 crossed with right arm, 26 with left arm. On left turning, 18 crossed with right arm, 21 with left arm. The right arm crossed 23 times to 47 with the left arm. This fact the author explains by stating that there is in right-handed men a better control over the right arm than the left arm, and during the loss of equilibrium, that is extreme in a certain proportion of those turned, there was a greater loss of control over the left than the right arm. The fact that only 5 of the 47 cross-pointed with the right arm on right turning is to be explained in this way: That for the right arm to cross-point on right turning, there is interference because of the large muscular development of the chest in right handed men. The following conclusions are offered: (a) In turning for past-pointing allowance must be made in some individuals for the extreme loss of equilibrium that results, in which case the cross-pointing is not an evidence of disease but possibly a hypersensitive condition of the end organ of the labyrinth. (b) In all cross-pointing, the left arm is more likely to cross-point than the right.

5. The falling reaction was found to be abnormal only 11 times in 257 times on right turning, and 10 times in 259 times on left turning.

In conclusion, the author reports a few cases where abnormal reactions occurred both from turning and from douching in men apparently normal in every respect. The author does not attempt to explain them.

Heitger discusses the Bárány tests. After a short historical introduction, the author gives the technic as worked out by Jones and his associates.

Speaking of the interpretation of the tests, the author mentions the following data as suggestive of a peripheral lesion:

1. A proportionate impairment of the function of the cochlea and kinetic-static labyrinth.

2. History or presence of tinnitus.

3. Proportionate impairment of the responses from the vertical canals and from the horizontal canals.

4. A proportionate impairment of nystagmus and vertigo.

On the other hand, the following suggest a central lesion:

1. Normal cochlea with impaired or nonresponsive canals. 
2. Normal responses from the horizontal canal, but impaired responses from the vertical canals, or vice versa.

3 . Normal nystagmus but impaired vertigo from the horizontal canal or vice versa.

4. Normal nystagmus but impaired vertigo from the vertical canals, or vice versa.

5. Normal nystagmus and vertigo from any semicircular canal but (a) impaired past-pointing in any direction of any extremity, or (b) impaired or absent normal falling.

6. Spontaneous verticál nystagmus.

7. If the semicircular canals of one side are nonresponsive and there exists a nystagmus to that side.

8. The production of conjugate deviation of the eyes instead of nystagmus.

Before pointing out the various ways in which a routint examination of the labyrinth can be of service, Jones corrects two misconceptions held by various otologists; misconceptions which have interfered with a universal adoption of these tests by the otologic profession.

As to the first misconception, namely, that a study of the internal ear and its intracranial pathways is a neurologic work, the author rightly insists that although the information may be of neurologic value, it is elicited by ear tests and hence is an otologic study, to the same degree that an eye examination, although of value to the neurologist, is distinct!y an ocular study.

As to the second misconception, namely, that such examinations are generally regarded as being extremely difficult, the author states that the entire physiology of these ear tests may be summed up in four sentences as follows:

1. The eyes are always drawn in the direction of the endolymph movement.

2. The vertigo is always in a direction opposite to the endolymph movement.

(a) Past-pointing is always in a direction opposite to the vertigo.

(b) Falling is always in a direction opposite to the vertigo. Stated differently, all the objective phenomena, the eye-pull (the slow component), the past-pointing and the falling, occur in the direction of the endolymph movement. 
As to the value to the otologist of these tests, the author mentions :

1. In the routine study of ear cases.

2. In determining the cause of vertigo.

2. In intracranial localization.

Jones writes on the value of the ear examination to the neurologist, emphasizing the aid given in making a differential diagnosis between peripheral and central lesions, and in the localization of central lesions. The author warns the enthusiast that the ear examination is not for the purpose of making a neurologic diagnosis; it merely gives additional data by a series of refined experiments, to the other methods at the command of the neurologist. Obviously, in order to obtain reliable data from an ear examination, it is essential that the technic of examination should be accurate and painstaking.

Jones states in elementary terms the physiologic basis for the results brought out by the vestibular tests and concludes with a statement of the standard for entrance in the Aviation Section of the Signal Corps of the U. S. Army.

Lemere has studied the oculomotor reaction to labyrinth stimulation from the point of view of the actual anatomic position of the canals and their physiologic relations to the movement of the head on the body, with the position of the body vertical and immobile. He concludes that there is a direct relationship between stimulation of the following canals and the action of the following muscles: the superior canals and the superior and inferior recti; the horizontal canals and the internal and external recti, and the inferior canals and the obliques. Also the horizontal canals are stimulated by the movements of the head nearly in a horizontal plane, the superior in a longitudinal plane, and the inferior in a transverse plane.

The erroneous conception of the positions of these canals should be corrected and they should be called horizontal, longitudinal and transverse, respectively. :

Lewis has observed that the influence of altitude on the hearing and the motion sensing apparatus of the ear is negative.

Parsons and Segar examined 100 naval aviators to determine if there was any correlation between the equilibrium 
tests as established by the Bárány chair and actual flying ability and have come to the conclusion that no such correlation exists.

Robertson describes some new methods of testing an aviator's ability to withstand sudden variations of atmospheric temperature and pressure at different altitudes.

The apparatus employed is a steel cabinet to which a vacuum pump is attached. The cabinet is supplied with a mercurial altigraph, the scale of which is marked to represent the vacuum in feet of altitude for each one-half inch. This altigraph will register from the earth's surface to an altitude of 25,000 feet. A window permits observation of the applicant during the test. The cabinet is air tight and provided with four pitcocks, one for connection with the altigraph, one for a negative pressure gauge, one to allow air to enter the cabinet, and the other connecting the vacuum pump. In subjecting a man to this test of rarefaction of air, he is subjected to the regular physical tests for blood pressure, pulse, muscular tone and rotation, both before and after the test in the cabinet. In the cabinet the air is exhausted at the rate of 1,000 feet altitude per minute until he has reached a height of 6,000 feet. He is kept in this rarefaction for a certain length of time, then a fall is simulated by allowing air to enter the cabinet, and the time it takes to bring the pressure to that of the earth's surface represents a rapid or slow descent. The object is to compare results of tests before and after subjecting patient to this rarefaction, to see what influence the latter has upon the former, and if any deductions can be made concerning which men would make the best aviators. The following are offered :

1. A man whose labyrinth is stimulated by a trial flight would be more acute than one in whom the labyrinth became less active.

2. A man whose muscle tone is more, or at least as great, after a trial would be better than a man whose muscle tone is impaired.

3. A man whose blcod pressure is elevated would be better than if the blood pressure were lowered.

Scruton discusses results in examining applicants for the Aviation Service. The author presents a record card showing the various reasons for rejection. Of 1,364 flyẹrs examined, 
514 , or 38 per cent, wcre rejected. Only 21 out of the 1,364 flyers were rejected for failing to respond correctly to the rotation tests. The author lays stress upon the careful attention to the minutest detail relative to technic, stating that the cause of cross-pointing and divergent pointing is absolutely an improper position of the head during rotation. The flyer must have a perfect aural mechanism, perfect vision, no .fundus changes, excellent heart and lungs, sound teeth and no form of hernia.

Stimson states that the static labyrinth is not the only organ of equilibrium, as it is in intimate connection with other special senses, such as sight, touch, muscle and joint sense in the maintenance of balance. But the end organ of the static sense differs from the others in that its only function is that of the maintenance of balance, whereas with the others that is merely a collateral function. Therefore, whenever perfect equilibration is interfered with and the sensation.of vertigo is produced, the attention should chiefly be directed to the static labyrinth.

The various conditions causing vertigo are:

1. Primary disease of the labyrinth, labyrinthitis of the various types, hemorrhage or effusions; embolus of the labyrinthine artery, e. g., air embolus in caisson workers ; irritation of the labyrinth occurring during a middle ear inflammation, such as acute otitis media; sudden destruction of the labyrinth, rarely by trauma, but usually by hemorrhage or serous effusion, in diabetes, Bright's disease, or where the vascular system is affected; neuritis of the eighth nerve resulting from some chronic focus of infection, such as chronic disease of the faucial tonsils, pyorrhea alveolaris, etc.; most frequently of all a primary chronic degenerative process within the labyrinth, independent of syphilis or infectious fevers.

2. Toxemias affecting the vestibular apparatus, such as ptomain poisoning, constipation, alcohol, quinin, tobacco, lead poisoning, nephritis, gout, rheumatism, syphilis and infectious fevers such as scarlatina, typhoid, mumps, etc.

3. Definite lesions within the brain itself along the pathways from the ear, such as tumor, hemorrhage, thrombus, infarct, abscess, gumma, tubercle, specific neuritis, multiple sclerosis, syringomyelia, polioencephalitis or meningitis.

The information to be derived from the ear tests consists of 
the presence or absence of normal reactions, or their deviations from the normal. If after stimulation, there occur no reactions whatsoever, no nystagmus, na vertigo, no past-pointing, no falling, etc., the lesion is either in the labyrinth or the eighth nerve. If stimulation of the labyrinth evokes perfectly normal responses, nystagmus and vertigo, there is evidently no impairment of the vestibular apparatus, and if it is for a cause of dizziness that we are searching, we must look elsewhere for something that is producing an irritation of the balance mechanism. If any of the responses goes through normally, the labyrinth and eighth nerve as the seat of the lesion are eliminated. If stimulation of the ear fails to produce any nystagmus, there must be a lesion along the pathway from the ear to the eyes, in the vestibulocular tract. If no vertigo results, there is a lesion along the pathway from the ear to the cerebral cortex, the vestibulocerebellocerebral tract.

If, after stimulation, the patient shows nystagmus and no vertigo, or vertigo and no nystagmus, the lesion is not labyrinthine. The presence of normal nystagmus with absence of vertigo would indicate a normal tract from the ear to the eyes, but an involvement of the other pathway, the one from the ear to the cerebrum, after the two have divided into their individual tracts, i. e., between Deiters' nucleus and the cerebral cortex. The presence of a normal vertigo and the absence of nystagmus would indicate a lesion along the fibers going to the eye muscle nuclei at some point beyond the division of the two pathways into their individual tracts, i. e., between Deiters' nucleus and the posterior longitudinal bundle.

In conclusion, the author summarizes as follows: The static labyrinth is the essential organ balance.

The labyrinth, together with its various nerve pathways, constitutes the vestibular apparatus or balance mechanism.

A disturbance of any portion of the vestibular apparatus gives rise to vertigo.

It is only a disturbance of the ear or its associated pathways, and nothing else, that can induce vertigo. When disease in remote organs causes dizziness it is only because of a definite influence on the ear mechanism.

In these tests we now have an accurate and scientific method of determining the integrity of the internal ears, the eighth 
nerve, and the pathways through the medulla oblongata, the pons, the six cerebellar peduncles, the cerebellum itself and the cerebral crura to the cerebral cortex.

In-cases of vertigo of doubtful etiology, examine the vestibular apparatus.

Swan and Iske examined 110 individuals with regard to the time of commencement and duration of nystagmus in the caloric test. They used seven ounces of water at $60^{\circ} \mathrm{F}$. The time for the water to flow out of the irrigator was 60 seconds. In forty-one instances the average time of onset was 50 seconds; the total duration of nystagmus, 37 seconds. They observed that there seemed to be no constant duration of the nystagmus and no constant time of onset, and that in health these times varied in different individuals. In thirteen instances no nystagmus was obtained under the given conditions, from which they deduce that $60^{\circ} \mathrm{F}$. is not cold enough and $55^{\circ} \mathrm{F}$. would be better. In neurasthenic conditions, nystagmus is prolonged; in one case 75 seconds' duration was noted. After two months' rest this period was reduced to 25 seconds.

$$
\text { III.-Diseases of ThF, External. Ear. }
$$

Henderson, G. E. W.-Deafness Due to the Placing of Candle Grease in the External Auditoty Meatus. J. Laryngol. Lond., 1918, XXXIII, 61.

Henderson reports a case of deafness due to the placing of candle grease in the external auditory meatus. The patient had placed a cone of grease into the meatus to keep out the noises of the city at night. The grease had melted and molded itself to the drum, which gave the appearance of a drum in chronic cararrhal otitis media. Heat by means of the hot water bag loosened the mold of grease from the drum.

This can illustrate what harm may be done through the agency of the lay press in offering its readers hints on matters pertaining to health.

IV.-Nonsuppurative Diseases of ThF. Middle Ear; OTOSCLEROSIS.

1. Brady, A. J.-Ossiculectomy in Chronic Adhesive Otitis. J. Laryngol., Lond., 1918, XXXIII, 50.

2. Emerson, F. P-Changing Methods add Advances in the Treatment of Progressive Deafness Following Chronic Hyperplastic Otitis 
Media (Second Communication). Ann. Otol., Rhino. \& Laryngol., St. Louls, 1918, XXVII, 1250.

3. Frederick, M. W.-Otosclerosis. N. York M. J., 1918, CVII, 152.

4. Gluck, Chas.-Common Deafness: Its More Accurate Handling. Med. Rec., N. Y., 1918, XCIII, 410.

5. Maybaum, J. L.-Factors in the Causation of Tinnitus Aurium. N. York M. J., 1918, CVII, 780.

6. MaKenzie, Dan.-Medlcation of the Middle Ear per Tubam. J. Laryngol., Lon., 1918, XXXIII, 118.

7. Pollock, H. L.-The Treatment of Otosclerosis from an Etiologlc Standpolnt. Illinols M. J., Chicago, 1918, XXXIV, 268.

8. Sautter, C. M.-Pilocarpine in Chronic Deafness. N. York M. J., 1918, CVIII, 592.

9. Sonnenschein, Robert.-Proper Diagnosis as a Guide to Prognosis and Operative Treatment of Impaired Hearing. Illfnols M. J., Chicago, 1918, XXXIV, 324.

Brady discusses the influence of ossiculectomy in chronic adhesive otitis, from his experience in three cases. Tinnitus was the distressing condition for which the operation was performed. One case was a failure, one a success as regards both the tinnitus and the hearing, but as this case was not followed up, nothing can be said about permanent improvement. The other case operated twenty years ago shows relief of tinnitus and improved hearing at the present time, thus proving that the universal pessimism expressed by his colleagues concerning the permanent benefit from this procedure is not justified.

Emerson in this second communication concerning the etiology and treatment of progressive deafness following chronic hyperplastic otitis media, presents several case reports illustrative of the modern conception of this frequent malady.

This conception is that the etiology consists in a chronic infection subject to acute exacerbations with varying degrees of virulency, constantly tending to invade continuous as well as remote structures by continuity or through the lymphatics or blood stream. The foci of infection should be removed if possible, but there are secondary foci beyond our reach in many chronic cases. These cases must be treated on broad lines of corrected metabolism, hydrotherapy, out of door living, rest, etc., as well as locally, remembering that audition is only one function gone wrong in the symptom complex.

Gluck states that the majority of cases of deafness are due to three, and in a small percentage of cases to four, abnormalities found in the nose and throat, and that if these abnor- 
malities are properly corrected the deafness will be invariably improved and of ten cured. These abnormalities are:

1. The two faucial tonsils.

2. Adenoids and adhesive bands in the nasopharynx.

3. Infected sinuses.

Gluck warns against the removal of turbinates until sufficient time has elapsed to determine whether the correction of the above abnormalities would cause a return of the turbinates to their normal size. If after two or three weeks the turbinate tissue remains redundant this can be reduced surgically. Of course, this does not apply to cases of polypi and intractable sinus disease where removal of turbinate tissue is indicated.

Maybaum goes into considerable detail in discussing the various manifold causes of tinnitus.

In the first place, he divided all cases into two classes:

1. Tinnitus without defective hearing, due to functional disturbance of the auditory nerve center, functional disturbance of the labyrinth, or abnormal condition of the circulatory system.

2. Tinnitus with deafness, due to a pathologic condition in the external, middle or internal ear.

In the former class are those conditions due to arteriosclerosis, anemia, epilepsy, migraine, toxemias from overindulgence in alcohol, tobacco and drugs, such as quinin and the salicylates. Finally neurasthenia is a factor.

So many helpful suggestions are scattered throughout the article that it is impossible to present them all in a short abstract. For these a careful perusal of the original article is necessary, and it will prove time well spent.

The following are a few selected at random:

1. It is important in giving a prognosis, to select the facts as to the constancy or intermittency of the noise. The latter type offers a better prognosis, as the causative factor is less likely to be of a permanent nature.

2. Continuous noises may disappear only after the patient becomes completely deaf.

3. Relief following catheterization of the eustachian tube is a favorable sign. 
4. In general, the chances for recovery from tinnitus are less hopeful than the hope of relief from deafness.

5. It is important to remember that persistent and prolonged treatment is fraught with greater harm to these patients (with middle ear disease) than entire neglect of treatment. A far better plan is to give two or thrce courses of treatment of a few weeks' duration with sufficient intervals between them.

McKenzie has been treating chronic catarrh of the middle ear by means of an oily solution of iodin sprayed into the middle ear by way of the eustachian tube. The formula is:

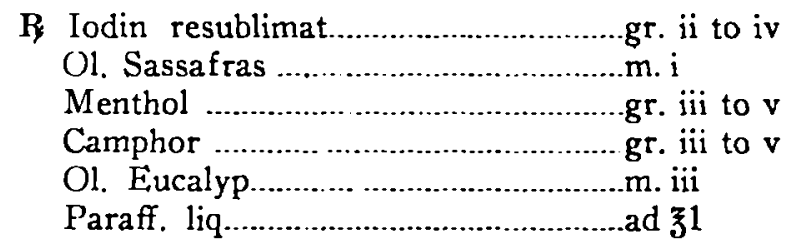

The stronger solution of iodin is used whenever possible, the feelings of the patient being the guide. Inflation and injections are made not less often than once weekly. The author has had success with this method. The liquid is sterile of itself. While the fluid should be warmed, it should not be too hot.

Sautter reports a case of chronic catarrhal deafness that was improved by the administration of pilocarpin solution by mouth for one week. Patient was instructed to take the medicine to the point of physiologic reaction or until a free perspiration was induced. Upon returning the following week, the patient stated that she had had a most profuse perspiration, with an immediate change of hearing, which was quite perceptible to herself as well as to her family. In testing the ear, Sautter noted an improvement in the lower tone limit from $55 \mathrm{~d}$. v. to $16 \mathrm{~d}$. v., or normal low limit. The hearing for voice had improved from 3 inches to 8 feet, and for the watch from zero to 1 inch.

Sonnenschein makes a plea for a careful differential diagnosis between chronic middle ear catarrh, otosclerosis and otitis interna, before deciding on prognosis and operative procedure. His conclusions are: 
1. To make an accurate diagnosis of the aural condition present, a thorough tuning fork examination usually is necessary.

2. Of the middle ear affections, the chronic catarrhal process is amenable to intranasal treatment, but in the socalled otosclerosis, treatment, especially operative, is not only useless, but often injurious both as regards the ear and the nose.

3. Involvement of the inner ear, as seen in the degeneration of the organ of Corti or the auditory nerve, is a contraindication to nasal operations or air inflations, except in that the latter may at times somewhat relieve the tinnitus.

4. In all nasal operations, particularly those upon the turbinate bodies, great care should be used to conserve the mucosa as much as possible, in order to avoid metaplasia of epithelium with consequent atrophic rhinitis.

OTOSCLEROSIS.-Frederick reviews the subject of otosclerosis pointing to the disappointing chapters which have been written into medicine when this malady was under discussion. The author's purpose in this communication was to point to some lines of investigation and to arouse enthusiasm in the breasts of some of the younger members of the profession in the hope that eventually some light might be shed upon this disturbing condition, rendered particularly so because the sufferers were usually those in the prime of life.

Pollock discusses otosclerosis from the standpoint of its being due to a disharmony of the ductless glands, which in turn is caused by an infective focus. The treatment then is directed to the femoval of any foci of infection, followed by an attempt to restore the harmony of the ductless glands by the hypodermic injection of adrenalin in gradually ascending doses, beginning with three minims and reaching ten to twelve minims at the end of eight weeks. Injections are given three times weekly. After an interval of four to six weeks the treatment is again started, followed by another rest, and so on. Improvement has been noted in some cases.

V.-Suppurative Diseases of The Middle Ear and Mastoid.; Facial, Nerve.

1. Beck, J. C.-Surgical Pathology of the Mastoid. Ann. Otol., Rhinol. \& Iaryngol., St. Louls, 1918, XXVII, 869. 
2. Bigelow, F. Nolton.-Types of Mastoid Structure with Special Reference to Their Differentlation by Means of Stereoradiography. Ann. Otol., Rhinol. \& Laryngol., St. Louls, 1918, XXVII, 887.

3. Black, W. D.-Indications for Radical Mastold Operation in Chronic Suppurative OtItis. J. Missour M. Ass., St. Louis, 1918, XV, 121.

4. Bodkin, H.-The Maxillary Antrum In Mastolditia. J. Laryngol., L.ond., 1918, XXXIII, 200.

5. Bowers, W. C.-Answer to Opponents of the Radical Mastold Operation. Laryngoscope, St. Louis, 1918, XXVIII, 790.

6. Dench, E. B.-Conditions Developing in Chronic Suppurative Otitis Media Which Should Constltute the Basis for Eremption from MHlitary Service. Laryngoscope, St. Louis, 1918, XXVIII, 717.

7. Freer, Otto T.-The Attic of the Middle Ear; Its Suppurative

Conditions. Illinois M, J., Chlcago, 1918, XXXIII, 189.

8. Gluck, Chas.-Common Deafness; Its More Accurate Handling. Med. Rec., N. Y., 1918, XCIII, 410.

9. Gluck, Charles.-Nasal and Aural Polyp1; Their Permanent Cure. Laryngoncope, St. Louls, 1918, XXVIII, 186.

10. Graham, H. B.-Osteosclerosis of the Temporal Bone in Chronic Suppuration. Laryngoscope. St. Louls, 1918, XXVIII, 872.

11. Howley, B. M.-Factal Paralysis In Ear Disease. J. Med. Soc., N. Jersey, Newark, 1918, XV, 270. 849.

12. Huntington, W. H.-Mastolditls. Mod. Rec., N. Y., 1918, XCIII,

13. Kahn, Alfred.-Paraffin in the Ear and Nose. N. York M. J., 1918, OVII, 681.

14. Kahn, Alfred.-Outlines of a New Instrument to Be Used in Skin Grafting in the Radical Mastold Cavity. Laryngoscope, St. Louls, 1918, XXVIII, 875.

15. Kerrison, P. D.-A Case of Abducens Paralysis Compllcating Mastoiditls. Brief Discussion of This Complication as an Indication for Surglcal Treatment. Med. Rec., N. Y., 1918, XCIV, 941.

16. Kerribon, P. D.-Report of a Case of Chronic Middle Ear Suppuration Treated by the Carel-Dakin Method, Following a Radical Operation Laryngoscope, St. Louls, 1918, XXVIII, 537.

17. Kyle, J. J.-The Modern Mastold Operation. Laryngoscope, St. Louls, 1918, XXVIII, 805.

18. Lathrope, G. H.-Acute Mastoiditis as a Complication of Infectlous Diseases. Jqur. Am. M. Ass., Chicago, 1918, LXXI, 451.

19. Lyon-Mercado, M.-A Note on the After-Treatment of the Radical Mastoid Operation. Lancet, Lond, 1918, CXCIV, 373.

20. Maclay, Nell.--Malaria Occurring Immedlately After Operation for Acute Mastolditis. J. Laryngol., Lond., 1918, XXXIII, 269.

21. McNaught, Harvard.-The Role of the Pseudodiphtheria Bacillus in the Pathogenesis of Ear, Nose and Throat Diseases. Ann. Otol., Rhinol. \& Laryngol., St. Louis, 1918, XXVII, 245.

22. Orton, Henry B.-Local Anesthesia in Mastold Operations. Ann. Otol., Rhinol. \& Laryngol., St. Louis, 1918, XXVII, 1261.

23. Prentiss, H. J.-To Determine the Location of the Lateral Sinus from External Markins. Also, the Approach to the Masto:d Antrum, as Modifled by Surface Markings. Ann. Otol., Rhinol. \& Laryngol., St. Louls, 1918, XXVII, 116. 
24. Price, C. E.-Middle Ear Infections. Illinols M. J., Chicago, 1918, XXXIV, 204.

25. Richards, J. D.-Report of a Case of Granuloma of the Mastold Simulating Subperiosteal Abscess. Ann. Otol., Rhinol. \& Laryngol., St. Louis, 1918, XXVII, 587.

26. Scarlett, Rufus B.-Earache and Its Management. N. York M. J., 1918, CVII, 631.

27. Schiller, A. Noah.-Faclal Paralysis Following Infection of the External Auditory Canal. N. York M. J., 1918, CVII, 403.

82. Sharpe, Wm.-Operative Treatment in Selected Cases or Chronic Perlpheral Facial Paralysis. Jour. Am. M. Ass., Chicago, 1918, LXX, 1354.

29. Smlth, J. Morrisette.-The Radical Mastoid Operation: IndIcations, Technlc and Results. Laryngoscope, St. Louls, 1918, XXVIII, 584.

30. Sobotky, Irving.-Severance of the Chorda Tympanl Nerve. Boston M. \& S. J., 1918, CLXXVIII, 224.

31. Steel, Geo. E.-Mrstolditis. N. York M. J., 1918, CVII, 63.

32. Wheeler, J. M.-Paralysis of the Sirth Cranfal Nerve Assoclated with Otitis Media. Jour. Am. M. Ass., Chlcago, 1918, LXXI, 1918.

Beck discusses the surgical pathology of mastoid disease. In acute mastoiditis two types are described: (1; The cell route, or confluent mastoiditis, and (2) the vascular route or osteophlebitic mastoiditis. In the confluent type, the bone bleeds easily, the lining membrane is edematous, the intercellular septa are broken down, pus is present. In the osteophlebitic type, the bone bleeds very little, there is little if any pus, the cells are well preserved and the membrane not very edematous. It is this latter type that produces the greater number of infections in the sinus, due to the extension from the venous infection in the bone.

In discussing chronic mastoid disease the author mentions ten varieties:

1. Osteofibrosis or sclerosis, in which the bone is converted into more or less solid bone.

2. Osteofibrosis with fistular tracts, in which in addition to the above sclerotic process, a few cells are met with and a number of necrotic tracts lined with granulation tissue.

3. Osteofibrosis, fistular tracts and cholesteatomatous infiltration.

4. Osteofibrosis, fistular tracts, cholesteatomatous infiltration with cavity formation of cholesteatomatous masses.

5. Tuberculous osteitis in which fistular tracts are present.

6. Syphilitic osteitis, usually a sclerosed bone. 
7. Actinomycotic osteitis, in which the cortex is practically riddled with fistulæ.

8. Reparative osteitis found in reoperated cases:

9. Foreign body in mastoid. (a) Sequestrum; (b) Any other substances.

10. Neoplasm. (a) Sarcoma; (b) carcinoma; (c) endothelioma.

The author promises a later presentation of the histologic changes by means of microphotographs.

Bigelow refers to the different types of mastoid structures and the importance of the different types in determining the result or course of an infection, and then goes on to show that these different types can be recognized by means of stereoradiography.

After referring to the usual classification of mastoids into three types, the pneumatic, the diploetic and the mixed, the author adds that in order to make this classification useful for clinical study and comparison, it must be made more descriptive and sufficiently comprehensive to include such other variable factors of mastoid structure as have clinical significance, among which are the thickness and density of the cortex and cell partitions, the number, distribution and arrangement of cells, and the location of the sinus. Both the diploetic and the pneumatic mastoid can be divided into three distinct anatomic types, each having both clinical and surgical significance peculiar to itself.

The three types of diploetic mastoids are:

'Type 1. Persistence of the infantile type in which the mastoid mass is diploetic. In this type the thin outer compact layer of the antral wall has increased in thickness from the periosteal side and is of extreme density; the inner layer of "fetal cells" is still seen; the mastoid mass is entirely diploetic, and the separating layer between the diploe and the cavity of the antrum is much increased in thickness.

Type 2. Persistence of the infantile type, in which the mastoid mass is dense. With exception of the mastoid mass, which is dense, the structures are as described under Type 1 .

Type 3. The mixed infantile and pneumatic mastoid, with the infantile characteristics predominating.

The radiogram, especially when a stereoscopic study is 
made, will practically always show the sinus to be far forward in the infantile types. When to this appearance is added a suggestion of cell structure towards the tip of the mastoid and a cellular area just above and behind the middle ear, the remainder of the mastoid appearing dense, in the writer's experience type 1 is to be confidently expected. When the entire mastoid appears dense, with the exception of a small cellular area, often but a faint suggestion, just above and behind the middle ear, type 2 is to be expected. When to one or the other of the above findings there is added a small group of large cells, though they be but faintly outlined, type 3 is to be looked for.

The three types of pneumatic mastoids are:

Type 1 . The pure pneumatic type, practically all of the cell structures containing air.

Type 2. The mixed pneumatic and infantile mastoid, with the pneumatic characteristics predominating.

Type 3. The "double decked" mastoid. The rells are arranged in two tiers, separated one from the other by a bony septum which in location and general appearance often closely resembles the internal table.

Dr. Isaac Gerber writes for the author a few paragraphs on how a thorough $\mathrm{X}$-ray examination of the mastoid is made and how the quality of the plate is determined.

Bigelow adds, in conclusion, that a proper $\mathrm{X}$-ray examination will in most instances reveal the type of mastoid, and that this. information, irrespective of what pathology may be revealed, should enable the observer to predict the clinical course and the prognosis of a middle ear infection with greater exactness and place therapeutic measures on a more scientific and less empiric basis. For example, if the $\mathrm{X}$-ray examination shows the mastoid to be one of the infantile types, the observer is thereby informed that in the case under consideration mastoid symptoms may not appear or may be very indefinite, and that the middle ear infection is quite likely to become chronic. Forewarned by this knowledge, he should prevent such a contingency by early drainage of the antrum. regardless of the absence of the classical indications for the performance of this operation. If, on the other hand, the radiogram shows the mastoid to be one of the pneumatic types, the observer 
should not hasten the patient to the operating table at the onset of stormy and threatening mastoid symptoms, but should remember Schwartze's dictum that, barring unusual symptoms, acute mastoids do not require operation unless the stormy mastoid symptoms continue unabated longer than eight days after incision of the drum membrane; in other words, he should wait a sufficient length of time for the reestablishment of atmospheric pressure within the mastoid cells.

The author has reported thirteen cases to illustrate the clinical and surgical significance of different types of mastoid structure, with special reference to their determination by means of the mastoid radiogram.

Twenty prints of radiograms of the mastoid and five illustrations of sectional bones accompany the article.

Numerous observations made by the author on the special operative difficulties of certain types of mastoids as well as their clinical significance have not been mentioned, because, as it is, the abstractor's enthusiasm for this subject has led him to devote to it more space than he had originally intended. A study of this paper in the original is heartily recommended.

Black divides the indications for the radical mastoid operation into two classes: The indications for immediate operation and the indications for a deferred operation.

The immediate operation is done to save life in such cases as present severe and dangerous complications, such as otitic brain abscess, epidural abscess, cerebellar abscess, thrombosis of the lateral sinus, extensive cholesteatomata, beginning symptoms of meningitis of otitic origin, sudden facial paralysis or labyrinthitis or labyrinthine irritation.

The deferred operation is indicated for the relief of symptoms, such as a discharge which resists the more conservative procedures, for two or three months; gradual reduction in the hearing when hearing in the other ear is good; pain in ear, over mastoid or over side of head; headache, particularly if it is less when the discharge increases; fever and malaise; vertigo; where life insurance was desired.

Bodkin reports on the condition of the maxillary antrum in fifty consecutive cases of mastoid disease coming to operation. His investigation tends to show that in cases of otorrhea the maxillary antrum is seldom sterile, but, particularly in 
chronic cases, is almost invariably infected, even though this has not proceeded to the length of obvious empyema of the sinus. As to whether this subacute or latent infection is of importance; whether it is primary and a cause of the mastoiditis or whether it is secondary to the otitis media, are questions difficult to decide. However, the author believes the mastoid healing is promoted by cleansing and antiseptic care of the maxillary antrum.

Bowers upholds the radical mastoid operation. After answering in great detail the various objections against the radical mastoid operating, and viting his technic, he tabulates his results in 112 cases and offers the following conclusions:

1. That many men are performing radical mastoid operations without having acquired reasonable proficiency.

2. That many radical mastoid operations are performed when not indicated.

3. That by many operators too little consideration is given to preservation of hearing.

4. That many cavities are not properly cared for, either by the surgeon or by the patient.

5. That it is possible to get dry cavities and improved hearing, and that these results are attainable in most cases.

6. That the operation is not dangerous and that complications are seldom unavoidable.

7. That the condition calling for operation is usually a very dangerous one and that it is too frequently dealt with lightly.

Dench discusses chronic suppurative otitis media from the military point of view, stating what types should and what types should not constitute a basis for exemption. In the first place, the subject is discussed from the point of view of the amount of the discharge, and, in the second place, from the information that can be obtained upon jhysical examination. From the point of vicw of the amount of the discharge, four types are considered: (1) Those where there is a constant profuse discharge; (2) a constant light discharge; (3) an intermittent discharge; (4) no discharge apparent to the patient. Where there is a constant profuse discharge, the patient should be exempted, if for no other reason than that the discharge is disagreeable to others and demands time and facilities in keeping it clean. Concerning the-other types, no 
decision can be reached from a consideration of the discharge itself. Other symptoms, such as vertigo, headache and deafness, are deciding factors. These cases of intermittent discharge occurring with each attack of "cold in the head" the author would accept for limited service.

The author's classification from the physical findings are as follows :

1. Cases of small central perforation. These are usually easily relieved by local treatment.

2. Cases of large kidney shaped perforation without caries of the ossicles and with the mucosa either dry or moist. Not sericus.

3. Cases of large kidney shaped perforation with the presence of granulation tissue. These cases should be accepted for observation and treatment, and results noted.

4. Cases with a perforation in the upper posterior portion of the membrana tympani with a sinus leading into the attic. These are dangerous and should not be accepted unless operated on radically.

5. Cases with complete absence of the drum, with sinuses leading in front and behind the short process of the malleus into the attic. Accepted if ear is dry and hearing up to standard. Otherwise should be operated radically.

6. Cases with small perforation through Shrapnell's membrane. Should be operated radically first.

The author closes his discussion with a plea for more reconstruction work in the form of the radical operation by competent men, not at Base Hospitals, but at the different institutions throughout the country, where this work is being done in civil practice. Many otologists past the age for active service could thus be rendering valuable service to the Government.

Freer discusses the suppurative conditions of the attic of the middle ear, first describing its topographic anatomy, showing that it is subdivided into a number of compartments with easily blocked intercommunications and communications with the mesotympanum.

The acute and chronic suppurative conditions are described. In the acute attic suppuration the earache is more severe than that of a simple mesotympanic abscess, and it is liable to persist after paracentesis. Also little or no discharge is liable to 
appear the first day or two, and mastoid complications are more apt to develop than in the simpler form of mesotympanic abscess.

Two types of the chronic attic suppuration are described: In one there is a large perforation of the pars tensa, with or without the presence of cholesteatoma ; in the other, the pars tensa with the manubrium mallei is usually intact, but above the processus brevis is seen a characteristic fistulous perforation remaining from the acute stage. There may or may not be polypi formation.

In the first group, thorough cleansing and drying treatment will often give excellent results, while in the second group the course of procedure is not so simple, because of the fact that the fistulous tract is not always very apparent. With special instruments the attic is washed and curetted and the tract enlarged if necessary.

Gluck claims to cure all discharging ears by correction of abnormalities in the nose and throat, just as mentioned in the previous section. In acute cases the nasopharynx is cleared out at the same time the drum is incised, and the tonsils removed as soon as the pain and fever have subsided. Surgical attention to the septum or other nasal fossæ structures is given subsequently.

Good results are claimed, whether the discharge is acute or chronic; the only difference being the time element. Gluck has found it unnecessary to advise the radical mastoid operation in a single case since treating his patients along these lines.

Gluck refers to the permanent cure of aural polypi by removing diseased tonsils and adenoids after removing the polypi.

Graham believes, contrary to the view held by Cheatle of London, that osteosclerosis of the mastoid can be a result of chronic suppuration instead of the cause.

Anteroposterior stereoscopic plates can demonstrate the condition.

After a few historical and anatomic remarks concerning the subject of mastoiditis, Huntington discusses (1) the etiology, stating that adenoid hypertrophy is one of the greatest etiologic factors in middle ear troubles and subsequent mastoid invasion; (2) symptomatology ; (3) diagnosis and aids to 
same; (4) indications and contraindications to the operation. The following indications are mentioned:

1. Cases of acute mastoiditis, with persistent pain on pressure over the tip or antrum. Persistence of fever after a successful paracentesis has been done, or in which a sagging of the posterosuperior meatal wall is found.

2. Cases of acute suppuration of the middle ear, with dizziness, vomiting, nausea,. or beginning facial paralysis, or with signs of intracranial or labyrinthian involvement.

3. Cases of long standing middle ear suppuration which resist all local measures, and because of good hearing and other reasons do not indicate a radical mastoid.

4. Cases of subperiosteal abscess.

Kahn speaks of the value of spraying paraffin over the skin graft in the radical mastoid cavity, stating that it seals the skin firmly in place and holds it there, and that it has the advantage over gauze in the fact that the latter might tear the graft loose when it was removed.

Kahn has devised two instruments to facilitate the introduction of skin grafts into the radical mastoid cavity. The first instrument is a thin plate of glass or metal, one and onehalf by three inches. This plate has an opening through its center and notches on one side of the plate, making a keyhole shaped opening. One end of the plate can be extended into a handle for easy manipulation. The other instrument consists of a rod gradually apically shaped at one end. At the other end a handle is attached, placed at an angle for easy manipulation and with the idea of not obstructing the view. The rod is grooved from apex to base by four gutters an equal distance apart. The rod is six inches long. Three inches from the apex the rod is notched to fit slot in first instrument. The apex of the rod is roughened by extremely minute projections, and the projection at the top of the apex is the highest.

Technic.-Holding the plate in the left hand, the graft is placed on the plate over the notch, the center of the graft corresponding to the round hole in the plate; and the rod with the apex up is held in the right hand. The plate is then passed down over the rod, the rod going through the round hole in the plate. The graft, now hugging the rod, is carried into 
the cavity, and by means of passing a long needle or "teaser" along the grooves in the rod the graft is spread out over the cavity. By suddenly pulling the rod away, the graft remains.

Kerrison reports a case of paralysis of the sixth nerve complicating mastoiditis, with complete restoration of function three days after a thorough mastoid operation. From a study of the literature, which reveals the facts that in mastoiditis associated with abducens paralysis, the mortality is much greater and the percentage of sixth nerve recoveries is much less in cases not operated upon than in those in which the mastoid operation is performed. Kerrison concludes that the occurrence with suppurative mastoiditis of paralysis of the sixth nerve of the same side, should be regarded as a positive indication for the mastoid operation.

Kerrison reports a case of chronic middle ear suppuration treated by the Carel-Dakin method. After the radical operation the wound cavity was flushed with Dakin's solution. A short gauze wick, saturated with the same fluid, was placed loosely in the cavity and a gauze dressing applied. On the following morning this dressing was removed and the following routine instituted: The nurse was instructed to fill the wound cavity every hour during the day with Dakin's solution, the patient lying for twenty minutes thereafter with the sound ear buried in the pillow, after which the fluid was allowed to run out and the ear protected with sterile absorbent cotton. At night-i. e., at the time of the last Dakin bath-the wound cavity was dried, then filled with chlorazine paste and a protective gauze dressing applied. The treatment was carried out for three successive days. Then once daily the wound cavity was thoroughly irrigated with Dakin's solution. The cavity, having been dried, was then filled with chlorazine paste and further protected by a pad of sterile cotton placed in the concha and held in position by collodion. This procedure was practiced daily during the first three weeks and thereafter on alternate days.

Epitomizing the effect, the author states that in actual duration of the postoperative treatment, this method did not in this case result in curtailment, as he was discharged as cured exactly two months after his operation. Chlorazine paste seems greatly to promote epidermization in certain parts and 
in others to retard it. The following advantages may be directly attributable to this method: clean

1. The bone cavity from start to finish seemed surgically

2. There were no masses of granulations to contend with.

3. E.pidermization over essential points, e. g., the posterior recess and the eustachian orifice, was particularly rapid. tient.

4. Treatment is practically without discomfort to the pa-

Kyle condemns the packing of the mastoid wound with gauze, and instead advocates simple drainage and irrigation by means of rubber tubing. With this method he claims:

1. The middle ear becomes dry, as a rule, in twenty-four hours after the simple operation.

2. The posterior bone cavity is sterile in a few days after operation, at which time the tube may be withdrawn. ing.

3. Healing is more rapid than by any other form of dress-

4. In exposure of the lateral sinus and dura, this method is the most logical and satisfactory way of draining.

5. An abscess in a mastoid process, ethmoid sinuses or antrum of Highmore, should as far as possible be drained, constantly aerated and flushed with warm salt solution, preferably twice a day. The result of long suppuration and slow healing is usually due to packing with gauze and lack of aeration.

Lathrope discusses the subject of acute mastoiditis as a complication of infectious diseases and presents facts and analogies from which he draws the following conclusions:

1. The army camp in question appears to have suffered this past winter an "epidemic" of acute mastoiditis.

2. This exhibition of mastoid infections is only one expression of the general streptococcus incidence in the camp.

3. The latter streptococcus invasion, in turn, is but a sideshow in the very widespread wave of streptococcus disease throughout Southern army camps.

4. It is peculiar in two points: (a) The dominant organism is the streptococcus viridans, and not a hemolyzing streptococcus, as appeared elsewhere; and (b) its chief expression 
is in the form of an unusually severe involvement of middle ear and mastoid tissues.

5. Measlés played a prominent part in giving the streptococcus a start in its work, and stands by itself as an etiologic factor in the development of the severer types of mastoiditis.

Lyon-Mercado discusses the after-treatment of the radical mastoid operation and gives the results of a series of twentyfive cases performed within the last year:

The subjective symptoms and objective indications of the twenty-five cases are tabulated as follows:

1. Presence of fetid discharges varying from over one year to six years' duration. 10 cases

2. Presence of purulent discharges of two years' standing with symptoms of headache, vomiting, vertigo and optic neuritis 2 cases

3. (a) Fistulous opening into the mastoid with cholesteatoma, 1 case ; (b) with cholesteatoma alone, 4 cases... 5 cases

4. Tuberculous disease of mastoid, (a) with facial paralysis of five months' duration before operation; (b) with no facial paralysis 2 cases

5: Presence of existing middle ear disease with lateral sinus phlebitis and thrombus in lateral sinus. 2 cases

6. Fetid discharge of two years' standing with, (a) single polypi ; (b) multiple polypi..................................... 4 cases

After-treatment: The posterior operative wound, except in the lateral sinus cases, was closed at the time of operation and healed by first intention.

Unless there was edema, intense pain, or a rise in temperature, there was no need to dress the cases till the fifth morning. The mastoid antrum was then syringed through the external concha-meatal opening (made expressly for drainage) with $3 \mathrm{oz}$. of $\mathrm{H}_{2} \mathrm{O}_{2}$ (dilution 1/2); or fresh eusol, half strength. The mastoid antrum was then cleaned out with two strips of ribbon gauze soaked in a solution of picric acid $(1 / 2$ per cent) in methylated spirit ( $71 / 2$ per cent). The ribbon. gauze varied from six to ten inches in length. A third strip of ribbon gauze soaked in the same solution was lightly packed into, and left in, the mastoid antrum till the next dressing. 
After the first dressing alternate day dressings only are re-. quired. The amount of the packing left in the mastoid antrum is lessened as it begins to heal over. About the fourth week the packing is discontinued, the ear being merely syringed.

Maclay reports a case of malaria occurring immediately after operation for acute mastoiditis, as an instance calling for keen judgment, because the advent of a rigor in association with any suppurative disease in the middle ear cleft suggests the onset of an intracranial complication which calls for immediate attention, but in the present case, the extent to which the mastoid was implicated by the pyogenic disease, the presence of healthy bone covering the sigmoid groove and bulb-the severity of the rigors, the apparently complete recovery on the following days and the absence of other signs of intracranial mischief-caused one to consider the possibility of some other explanation of the acute constitutional disurbance. This was found when the patient 2dmitted having been bitten by mosquitoes in France, and the finding of malarial parasites in the blood.

McNaught reports two cases of mastoiditis due to the pseudodiphtheria bacillus, concerning which organism the following summary is presented:

1. The pseudodiphtheria organisms occur normally on many surfaces and in mary tissues of the body. It is probable that under normal conditions, even the socalled virulent types are nonpathogenic but may become so by symbiosis or a depressed general or local state.

2. The organism, so far as is known, is not a mutation form of the Klebs-Loeffler bacillus, though at times resembling it in its morphology. Its behavior in culture towards sugars and the fact that it has its own opsonic index are additional proofs of its distinctiveness.

3. Negative results from guinea pig inoculations are not conclusive proof that it is a pseudodiphtheria bacillus, as virulent Klebs-Loeffler bacilli may give the same results.

4. In true infections with this organism agglutinin is formed and the serum opsonin is decreased. A mild bactericidal power of serum arises in patients, and a very pronounced bacteriolysin can be produced in experimental animals. 
Orton describes his method of procedure in the use of local anesthesia in mastoid operation. One-half hour before the time set for the operation $1 / 4$ grain morphin and $1 / 150$ grain atropin were given hypodermatically, and the $1 / 4$ grain morphin repeated at the time of the anesthesia. The skin was anesthetized along the line of incision from above the auricle to one inch below the tip of the mastoid, at about which point a deep injection was made to block off the auricularis magna nerve. Another nerve requiring blocking off is the occipitalis minor, which is about $11 / 2$ inches posterior to the extemal canal and on a level with the floor of the canal. Then the needle was pushed in deeply through muscle and under periosteum, also along posterior wall of the canal. The operation is begun after an interval of five to ten minutes. When the antrum is reached, it is filled with the solution, which is allowed to remain until the tip cells are cleared away. Novocain in the strength of $1 / 2$ to 1 per cent was used. From an experience on nine mastoids, the author notes the following results:

1. Perfect anesthesia without prolongation of the operation.

2. Absence of danger to pneumouia from inhalation.

3. Convalescent period shorter.

4. Postoperative pain much lessened.

5. It is to be recommended in all cases following pneumonia and empyema where ether is contraindicated.

Prentiss draws attention to the relation between the position of the lateral sinus and the curve of the supramastoid crest (third root of the zygoma). A very obliquely placed crest indicates that the sinus is well posterior to the field of approach to the antrum, and a horizontally placed crest indicates that the sinus is close to the field of operation.

The approach to the antrum is influenced by the supramastoid crest, because the crest indicates the petrous portion of the cerebral fossa. For instance, if the crest runs backward well above the external auditory canal, the cone of approach to the antrum may be made with little likelihood of exposing the meninges. On the other hand, if the crest runs backward just tangent to the canal, the approach must be made well below the crest.

The text of the article is much clarified by the illustrations. Price reports several cases of middle ear infections, illus- 
trative of the principle that the course and outcome can never definitely be prognosticated from signs and symptoms presented, hence he makes a plea for early paracentesis and a roentgenogram.

Richards reports an unusual case of apparent subperiosteal abscess in a child one year of age. Upon operating, however, there appeared not pus but a grayish yellow tumor occupying the site of the mastoid and completely filling it. The tumor had as its base the dura of the temporosphenoidal and cerebellar lobes. The vertical limb of the sigmoid sinus was obliterated. 'There was no posterior bony canal wall to the meatus and the anterior wall was largely eroded. Sarcoma was suspected, so the mass was curetted away. Microscopic examination revealed a granuloma and the patient made an uneventful recovery.

Scarlett contributes a paper for the general practitioner on earache, discussing its importance and emphasizing the fact that an. earache from middle ear infection should not go unrelieved for over twelve hours, but that an incision of the drum should be performed. He warns against the instillation into the canal of oily preparations, as they tend only to macerate the epithelium and obscure the picture.

Smith discusses in a most intelligent way the subject of the radical mastoid operation. Three reasons are offered for the attitude of some men in condemning the procedure:

1. The operation has- been recommended and attempted in many cases where it was not indicated.

2. It has been attempted by men who have not taken the trouble to thoroughly familiarize themselves with the technic.

3. Proper attention has not been given to the after-treatment.

To determine which type of cases demand the radical operation, the author divided the chronic infections into three classes :

1. Those cases of intratympanic infections with little or no involvement of the attic. These rarely if ever require a radical operation.

2. Those cases involving not only the tympanum but the attic, antrum, and-to a limited extent-the mastoid. 
These cases demand the nicest judgment in deciding for or against the radical operation.

3. Those cases involving the intratympanic attic, antrum and mastoid structures as well.

These are the cases in which the radical operation is most frequently indicated.

After discussing the technic of the radical operation and reporting ten cases, the author draws the following conclusions :

1. The radical mastoid operation is not indicated in all cases of chronic aural infections.

2. It is indicated in a certain percentage of chronic infections, and no other surgical procedure will answer its purpose.

3 . With the proper technic it is a comparatively safe operation.

4. The hearing in the average case-not in all-requiring a radical operation should be improved.

5. The hearing-allowing for the reduction due to removal of the drum, malleus and incus-depends on the amount of fibrous tissue allowed to remain or form over the internal wall.

6. The after treatment is most important, and its neglect will result in failure to obtain the desired results.

7. The hearing will be better where the tube remains open, the objection being that there may be a recurrence of the discharge at any time, due to a fresh tubal infection.

Sobotky reports a case of injury to the chorda tympani nerve during a paracentesis for acute otitis media. Patient complained of inability to taste and of a numb feeling over the right side of his tongue. A probe examination showed insensibility to touch, and tests with solution showed no taste in anterior half to two-thirds of the tongue on the side of the injury, except possibly at the very tip. Taste was present on the right posterior one-third.

Steel approaches the subject of mastoiditis from the standpoint of the general practitioner, and discusses the following points :

1. Necessity for operative interference.

2. Danger to life.

3. Danger to hearing.

4. Amount of deformity. 
5. 'Time for healing to occur.

6. Time required to be away from business.

In deciding concerning the necessity for operative interference, the following terminations should be kept in mind:

(a) The case may go on to spontaneous recovery with little or no treatment and function will be restored to normal, especially in children.

(b) It may recover as far as mastoid symptoms are concerned, but the ear will continue to discharge steadily or intermittently, the perforation in the drum membrane remain open, and function be progressively impaired.

(c) The patient may ultimately recover spontaneously after an unduly prolonged period of aural discharge, the perforation in the membrana tympani healing; but deposits, bands or adhesions may remain which impair function, give rise to a distressing tinnitus, and finally result in marked deafness.

(d) Complications may develop, with or without operation, which may result fatally or jeopardize life.

(c) The patient may undergo mastoidectomy and recover with or without impairment of hearing.

Laboratory aids, such as blood count, bacteriologic examinaton and $\mathrm{X}$-rays are mentioned as of service in reaching a decision.

The prognosis in a mastoidectomy done where there are no cranial complications and in a patient otherwise healthy is exceedingly good.

In a mastoidectomy done at the right time before destructive changes occur in the middle ear, the hearing will return to what it was before the operation.

As to length of time for the healing of the mastoid wound, the average is six weeks.

In an uncomplicated mastoiditis, the patient should remain in the house for ten days after operation and from business for at least two weeks.

Whalen discusses paralysis of the sixth cranial nerve associated with otitis media, the condition otherwise known as Gradenigo's syndrome. The condition is characterized by (a) acute otitis media (with or without external suppuration, and with or without mastoid reaction); (b) isolated paralysis or paresis of the abducens nerve of the side corresponding to the 
diseased ear, and (c) intense and extraordinarily persistent pain localized, not as ordinarily in the mastoid region, but in the frontal, temporal and parietal regions of the same side.

The anatomic explanation of the syndrome is thoroughly discussed.

Facial Nerve.-Howley presents a report of three cases of facial paralysis in acute ear disease. The diagnosis of the first case was acute otitis media with Bell's paralysis. In the second case, a facial paralysis occurred the day after a simple mastoidectomy for acute mastoiditis, and the diagnosis was a facial paralysis from pressure due to postoperative hemorrhage. The third case was one of facial paralysis due to pressure of the exudate from acute otitis media and mastoiditis before operation.

Schiller reports an unusual case in which there was middle ear infection and facial paralysis following a diffuse external otitis of months' duration. The patient was a diabetic, and after a radical mastoid operation under local anesthesia the infection and paralysis cleared up.

Sharpe describes a new technic for the operative treatment of chronic peripheral facial paralysis, the distinctive feature of which is the utilization of only one-half of the hypoglossal nerve for anastomosis to the entire peripheral cut end of the facial nerve, thus leaving a portion of the hypoglossal nerve in continuity to regain its own complete function, which it does within a period of two months. The latter is made possible by cutting several of the intact nerve fibers of the remaining half of the hypoglossal nerve and approximating them by a single suture to the peripheral cut portion of the hypoglossal nerve.

The technic is described as follows:

"By means of a small curved incision just posterior to the angle of the lower jaw, and anterior to the mastoid process (the ear lobe being held forward), the facial nerve is exposed as it crosses the styloid process externally: the nerve itself is now severed as close to the stylomastoid foramen as possible so that a peripheral portion of at leat ond-half inch is obtained for anastomosis. The facial nerve should always be exposed first, as it has bcen reported absent or rather 'not 
found' in several patients. Possibly the best landmark to use in finding the hypoglossal nerve is to expose the external carotid artery; just below its occipital branch the hypoglossal nerve curves forward and to the outer side of the main trunk of the external carotid artery to lie between the posterior belly of the digastric muscle externally and the hypoglossus muscle internally. By blunt dissection, the hypoglossal nerve can be easily exposed forward so that a portion of at least 1 inch, and still better, $11 / 2$ inches, is obtained for the anastomosis with the facial nerve. 'The entire hypoglossal nerve, within its sheath, and being held by its sheath, is now incised longitudinally in its midline by a small thin bladed scalpel, and its nerve fibers are now separated in the midline longitudinally for a distance of one inch at least; at the distal part of the bisection the outer half is now severed and its central cut end is brought backward and upward to be sutured, sheath as much as possible, to the entire peripheral cut end of the facial nerve: Small black silk sutures (waxed) on French needles are very satisfactory. No foreign material is placed about the anastomosis. After the facial anastomosis has been completed the small scalpel is again used to separate longitudirially and to cut several nerve fibers of the remaining half of the hypoglossal nerve in the same plane of the former incision. The central cut end of these fibers is now approximated to the peripheral cut portion of the outer half of the hypoglossal nerve by a single suture through their sheaths."

A modification is suggested for patients having only partial peripheral facial paralysis, in whom the reaction of degeneration is not present, and yet the paralysis is of such a character, owing to the deformity, contractures, conjunctivitis and other complications, that an attempt might be made to improve the condition. The cefitral cut portion of one-half of the hypoglossal is inserted into the facial nerve through a small right angled slit of its sheath and adjacent fibers.

In conclusion, the author warns that no patient should be operated on, no matter how complete the paralysis, unless it is definitely ascertained that the facial nerve is permanently injured, or a period of intensive treatment of at least ore year following the injury has elapsed without a definite improvement of the condition. 


\section{VI.-InTRACRANiAL COMPLiCATIONS.}

1. Ballou, David H.-Lateral Sinus Thrombosis. Three Cases. Laryngoscope, St. I rouis, 1918, XXVIII, 465.

2. Boot, G. W.-Cases Illustrating the Diagnosis of Intracranial Complications of Ear Diseases. Ann. Otol., Rhinol. \& Laryngol., St. J.ouis, 1918, XXVII, 213.

3. Braislin, Wm. C.-Brain Abscess Caused by Chronic Suppurative Otitis. N. York M. J., 1918, CVII, 446.

4. Braun, Alfred.-The Pathology of Sinur Thrombosis. Ann. Otol., Rhinol. \& Laryngol., St. Louis, 1918, XXVII, 461.

5. Braun, Alfred.-The Diagnosis of Slnus Thrombosla. N. York M. J., 1918, CVIII, 1069.

6. Dabney, V.-Two Cases of Unusual Wounding of the Lateral Sinus. Ann. Otol., Rhinol. \& Laryngol., St. Louis, 1918, XXVII, 607.

7. Dench, E. B.-Acute Meningitis. Laryngoscope, St. Louls, 1918, XXVIII, 501

8. Dickie, J. K. Milne.-Two Interesting Cases of Middle Ear Suppuration with Complications. J. Laryngol., Lond., 1918, XXXIII, 106.

9. Faulkner, E. Ross.-Two Cases of Sinus Thrombosis Which Presented Unusual Difficulties in Dlagnosls. Ann. Otol., Rhlnol. \& Laryngol., Bt. Louis, 1918, XXVII, 970.

10. Glogau, Otto.-A Case of Otogenous Temporal Abscess with Hemlplegla. Facial Paralysis and Aphasia; Cerebral Drainage, Decompression, Recovery. Ann. Otol., Rhinol. \& Laryngol., St. Loula, 1918, XXVII, 456.

11. Hastings, H.-Intracranial Compllcations of Diseases of the Ear, Nose and Throat. Callf. State J. M., San Fran., 1918, XVI, 620.

12. Kahn, Alfred.-A Case of Labyrinthal Meningitjo with suggestions for a Now Labyrinth Operation. Med. Rec., N. Y., 1918, XCIV, 930 .

13. Layman, D.-Report of a Case of Purulent Leptomeningitls of Otitlc Origin. Ann. Otol., Rhinol \& Laryngol., St. Louls, 1918. XXVII, 149.

14. Page, John R.-Report of a Case of Mastoidectomy for Acute Suppurative Otitis Media, Followed Later by Faclal Paralysis, Almost Total Deafness, Meningitls, Death. Ann. Otol., Rhlnol. * Laryngol., St. Louls, 1918, XXVII, 589.

15. Perkins, Chas. E.-Leucocytosis of the Spinal Fluid in the Dlagnosis of Meningitis. Ann. Otol., Rhinol. \& Laryngol., St. Louls, 1918, XXVII, 974.

16. Perking, Chas. E.-A Case of Meningitis Treated by Labyrinthectomy and Decompression. Laryngoscope. St. Louis, 1918, XXVIII, 695.

Sinus Thrombosis.-Ballou reports three cases of lateral sinus thrombosis. The thrombus was on the right side in all cases. Ages 15, 23, 20. Chronic history of aural suppuration 10, 17, and 6 years. Immediate causes: Cold, influenza or operation. Organisms: B. pyocyaneous, staphylococcus and streptococcus pyogenes, and streptococcus hemolyticus. The 
symptoms were characteristic, showing the usual triad: chills, intermittent fever and sweats. Two of the patients while in the hospital had rigors lasting one-half hour. The highest temperatures were $103,103,105$. There was a marked flush of the right cheek only-i. e., the side of the lesio\%.

The aural findings: Case 1.-Drum destroyed, tympanic cavity dry but filled with epithelial debris. No mastoid swelling. Case 2.-Small round perforation in middle of posterior half of drum, scanty discharge, later absolutcly dry; no swelling of mastoid. Case 3.-Drum destroyed, tympanic cavity filled with granulation tissue; moderate discharge and pulsation visible. Edema over the mastoid.

The blood cultures and eye grounds were negative in all cases, also the lumbar puncture.

Leucocyte counts: $30,000,12,000,16,000$.

$\mathrm{X}$-ray showed small sclerosed mastoid, sinus far forward but no thrombus.

The findings at operation were in the main identical in all cases. The mastoid was sclerosed but vascular. Pulsating pus under tension was present. The lateral sinus was superficial, very far forward, gangrenous or covered with lymph and granulations. Pulsations were visible or palpable, even with presence of thrombus. Tympanic cavity filled with granulation tissue and cholesteatoma.

The treatment was a radical mastoid operation Removal of all diseased bone in contact with the sinus until apparently healthy sinus was reached in both directions.

As to ligating the jugular vein, the author believes that where the thrombus can be removed and free bleeding obtained at both ends, the jugular vein need not be ligated. 'This was the treatment in two cases, and in the third the ligation of the jugular had no effect, as there was no thrombus in the jugular vein and free bleeding was obtained in the bulbar end after ligation.

Braun offers a very instructive discussion on the subject of the pathology of sinus thrombosis. So many interesting and important topics are presented in every paragraph that no abstract can do justice to the article. Nothing more then will be attempted than to refer briefly to a few of the salient points brought out by the author. The causative factors in the pro- 
duction of a thrombus are: (a) slowing of the blood stream; (b) increased agglutinability of the blood plateleta; (c) an increased coagulability of the blood plasma, and (d) changes in the vessel wall.

As to the manner in which thrombosis of the lateral sinus occurs as a complication of middle ear and mastoid disease, the following ways are mentioned:

1. The inner table of the mastoid over the sinus may be diseased and an abscess form between the sinus and the inner table. This results in an inflammation of the outer sinus wall which in turn leads to the formation of a thrombus within the sinus.

2. The inner table over the sinus may be diseased and cause an extension of the inflammatory process to the sinus wall without the intermediation of a perisinus abscess. The phlebitis results in a thrombus formation.

3. A thrombus may form in one of the smaller veins of the mastoid process and extend into the lateral sinus.

After discussing the various changes occurring in a thrombus as well as concomitant changes brought about in adjacent and more remote structures, the author mentions the possible end results of a thrombus in the sinus:

1. The patient dies of general sepsis before the clot breaks down.

2. The clot breaks down in the center, and the pus finally breaks through the outer wall of the sinus, so that the abscess within the sinus communicates with the perisinus abscess.

3 . The pus within the sinus breaks through the visceral wall of the sinus and produces a cerebellar abscess or a meningitis.

4. The thrombus organizes and results in obliteration of the sinus.

5. Part or all of the thrombus becomes absorbed, resulting in recanalization of the sinus.

Braun, in discussing the subject of the diagnosis of sinus thrombosis divides the symptoms into those which are due to the general systemic poisoning and those which are due to the local inflammatory lesion in the affected sinus. The former symptoms are common to all cases of sinus thrombosis; the latter symptoms differ according to the sinus or sinuses involved. The symptoms due to the local lesion in the sinus 
are further subdivided into those which are caused by the inflammation in the sinus wall, and those which are the result of obstruction to the venous circulation, caused by the thrombus.

A. Symptoms referable to the local lesion in the lateral sinus:

I. Symptoms due to the inflammation of the sinus wall-

1. Pain may or may not be present. Nothing characteristic.

2. Optic Nerve Changes.-Those occur in only a moderate number of cases. The character of the lesion is a neuritis or hyperemia. Atrophy is rare. Marked visual disturbance is uncommon.

3. Paralysis of the sixth nerve sometimes occurs.

4. Peryngulitis producing a tender cordlike mass at the side of the neck.

5. In volvement of the glossopharyngeal nerve, causing paralysis of the soft palate.

6. Involvement of the vagus nerve, giving rise to hoarseness and slowing of the pulse rate.

7. Involvement of the spinal accessory nerve, causing spasmodic contractions, or paralysis of the sternomastoid and trapezius muscles.

II. Symptoms due to interference with the venous circulation:

1. Griesinger's sign-a painful swelling at the point of exit of the mastoid emissary vein. Not a diagnostic sign.

2. A painful swelling in the posterior triangle of the neck, due to a spreading of the thrombotic process into the posterior condyloid vein. Not a diagnostic sign.

3 . Gerhardt's sign or an unequal fullness of the external jugular veins on the two sides. Not diagnostic or reliable.

Examination of an exposed sinus may or may not give information of diagnostic importance. Usually, when a perisinus abscess is present, there is no thrombosis, but there are exceptions. Discolorations in the wall are suggestive. The presence or absence of pulsation in the sinus is of no diagnostic value. If the wall has a doughy feel or a resistant feel, or if the wall is collapsed, it speaks for a thrombus.

B. There are no local symptoms which are characteristic of thrombosis of the superior or inferior petrosal sinuses.

C. In infectious thrombosis of superior longitudinal sinus, 
the local symptoms are edema of the soft tissues in the frontal, parietal and temporal regions.

D. Symptoms referable to the local lesion in the cavernous sinus :

I. Symptoms due to inflammation of the wall-

1. Pain, either a generalized headache or facial neuralgia. Pain may be absent.

2. Optic nerve changes comparatively infrequent. When present, the change is either a neuritis or choked disc.

3. Paralysis of the third, fourth, first division of the fifth and sixth nerves. Paralysis of the third is present in almost every case.

II. Obstructive symptoms are:

1. Exophthalmos, constant and early. Soon bilateral; not painful on pressure.

2. Chemosis, constant.

3. Edema of lids, constant.

4. Edematous swelling in pharynx, occasionally.

The distinguishing feature between cavernous sinus thrombosis on the one hand and orbital abscess or cellulitis, ethmoiditis or acute conjunctivitis on the other hand, is that only in the former are there paralyses of the ocular muscles; that the symptoms become bilateral in a few days; that pressure on eyeball is painless; that there is absence of characteristic symptoms of the other diseases.

Passing from a consideration of the local symptoms, whether inflammatory or obstructive in nature, Braun next discusses the general symptoms, which are the same irrespective of the location of the thrombus.

General symptoms of sinus thrombosis:

1. Temperature, usually high and remittent. May be regular or normal.

2. Chills, accompanying each rise in temperature. Chills may be absent.

3. Sweats usually follow the chills. May occur in the absence of chills.

4. Rapid pulse.

5. Gastrointestinal symptoms simulating typhoid.

6. Vertigo, not common.

7. Disturbances of the sensorium are rare. 
8. Metastases, more common in the lung, but may occur in any part of the body.

From the above enumeration of symptoms, local and general, it is seen how uncertain the diagnosis may be at times. Typical cases are easy; others almost impossible.

Blood culture is mentioned as one of the most valuable diagnostic aids, but a negative culture does not exclude sinus thrombosis. Meningitis may give a positive culture, but this can be differentiated by means of the cerebrospinal fluid examination. If other than the streptococcus is found, some other condition should be suspected. Among the more frequent conditions causing bacteremia and which should be excluded before a diagnosis of sinus thrombosis is made, the following are mentioned: Endocarditis, pneumonia, typhoid. tonsillar and accessory sinus infections, scarlet fever, erysipelas and meningitis.

Aspiration of the sinus for diagnostic purposes is not without danger and not always trustworthy. Incision may be necessary, and even then there may occur free bleeding from either end in the presence of a thrombosis.

Finally, sinus thrombosis may be mistaken for malaria, typhoid, pneumouia, erysipelas, septic endocarditis, meningitis, grippe, tonsillitis and cervical adenitis, and the author discusses briefly the distinguishing features of these diseases.

Dabney reports two cases in which the lateral sinus was wounded in an unusual location during the performance of the radical mastoid operation. In the first case the sinus was wounded in curetting what was supposed to be the roof of the antrum. In the second case the sinus was wounded during the elevation of the insertion of the sternomastoid muscle from the mastoid tip.

Dickie reports two cases of sinus thrombosis which are clear from an aurist's point of view, but which received a variety of diagnoses prior to the aural examination. Which illustrates the importance of examining the ears in all cases with rigors and severe illness of obscure origin.

After the first case had been operated twice, the first operation consisting of the mastoid and sinus operation, and the secondary consisting of free exposure of dura over temporal 
region and Newman's operation on the labyrinth, the patient had a rise of temperature with acute pain in the left side and arm, which was probably an infarct of lung. Patient recovered. The second case had septic infection long before seen by the aurist. This patient died.

Faulkner describes two cases of sinus thrombosis which presented unusual difficulties in diagnosis. 'The first case was that of a boy with acute suppurative otitis media. The discharge had practically stopped, and the patient would have been considered well except for pyemic temperature. A simple mastoid operation performed and dura and sinus exposed, but both appeared healthy. Instead of progressing favorably, patient continued to have a pyemic temperature, pulse rate usually under 100 , the mastoid to all appearances undergoing resolution, apparently an embolic process in the right shoulder, with streptococcus irridans in the blood. The focus was not thought to be in the ear, because no case of streptococcus irridans in the blood had been reported with a primary focus in the ear. However, as a last resort, the sinus was explored and a perisinus abscess around the bulb was discovered. The culture from the pus in this region showed streptococcus hemolyticus. The patient recovered.

In the second case the patient had a discharging ear three weeks previously, but none at the time of examination. The patient complained of pain over the frontal region and said he had had a chill every day for the past week. In spite of daily elevations of temperature to 104 with chills, there were no local ear symptoms. There was no chill or fever on the fourth day, but on the fifth day there were two sharp upward elevations of temperature. Operations revealed liquid pus in the sinus, but no perisinus abscess or granulations on the surface.

Brain Abscess.-Braislin reports three cases of brain abscess following chronic suppurative otitis media. in all of which there were few cerebral symptoms. In none of the cases was there noticeable slowing of the puse. There was a history of purulent discharge from the ear and recurrent attacks of pain in the ear or in the corresponding side of the head.

Two cases were abscesses of the left temporosphenoidal 
lobe, in one of which was noticed a typical amnesic sensory aphasia. Two recovered.

Glogau reports a case of otogenic temporal abscess on the left side, with aphasia, and hemiplegia and facial paralysis on the right side, cured by drainage. The interesting features of the case were the following: At the time of the radical mastoid operation the abscess was in the latent stage, hence no brain exploration was attempted in the absence of any suspicious dural changes. Over two weeks later, manifest symptoms developed, at which time the brain was explored, even in the absence of dural changes. The abscess was located at the upper temporal convolution quite away from the middle ear focus.

The infection was an indirect one, either by means of the lymphatics, the sheaths of the arteries or nerves, or by extension of thrombophlebitis of the pial vessels.

The author explains the crossed convulsions, hemiplegia, hemianesthesia, facial paralysis as due to the remote action of the increased intracranial pressure upon, and of the inflammatory reaction around the cortical centers within the anterior, posterior, central and inferior frontal gyri.

MENINGITIS.-Dench presents the subject of otitic meningitis, and while including under the term otitic meningitis in its broadest sense such conditions as extradural abscess and serous meningitis, the chief purpose of the author in the present communication is to give his views on the treatment of otitic leptomeningitis. These cases he divided into (a) fulminating, (b) frank, and (c) latent types. The fulminating present the well recognized symptoms of meningitis, as easily diagnosed, and terminate fatally in from twelve to forty-eight hours. While this type may be due to an otitic infection, the author believes that many of these cases can be better called coincident meningitis, as autopsy has frequently failed to reveal the connection with theotitic infection. The frank cases likewise present the well recognized symptoms of meningitis and offer no difficulties in diagnosis. But the latent cases are the ones offering the greatest difficulty in diagnosis and the ones which can be given most help by surgical intervention.

In these cases the first symptoms which present themselves are those of general malaise, moderate temperature, ranging 
from 99 to 101, some headache and vomiting, particularly when these occur after an operation on the middle ear and mastoid.

As regards treatment, the author advises:'

1. Removal of the primary focus of infection.

2. Exposure of a large area of dura, with subdural drainage in cases of fulminating type.

3. Repeated lumbar punctures in all cases.

In conclusion, the author holds out a hope for every case when surgical intervention is permitted, unless they are actually in extremis when seen by the surgeon.

Kahn reports a case of labyrinthal meningitis. with recovery, which he attributes to the fact that the diseased area involved the inner wall of the middle ear, that this wall was soft and necrotic, and that it was further accidentally injured at the time of the radical operation in an anxious endeavor to remove all necrosed bone; that it was through this passage by way of the internal auditory meatus that the labyrinth was destroyed and that meningitis took place. This wall afterwards broke down, and the author feels that the patient recovered because there was direct drainage from the meninges through the internal auditory meatus, through the internal ear, middle ear, etc., through an accidentally artificially created opening.

Taking his cue from this fact, Kahn saw the possibilities of a new labyrinth operation in cases of meningitis secondary to labyrinthitis. His technic is as follows:

1. Performance of the radical mastoid operation.

2. Extension of the radical operation to its furthest limits. The facial ridge must be cut down to its very last shaving. The sinus should be exposed from above the knee down toward the bulb as deeply as possible. The bone in front of the sinus must be cut away as deeply as possible, exposing the soft parts beyond; the dura outlining the middle cranial fossa above the middle ear should be exposed as deeply and as far forward as possible-in fact, the dura should be exposed over such an area that it will form a junction with the dura covering the sinus region, and the exposure should extend as far forward as the superior semicircular canal. The dura outlin- 
ing the middle and posterior fossæ and covering the sinus should be exposed.

3. The promontory is now opened, and a direct passage is made through it, so that the internal auditory meatus communicates through a direct passage with the middle-ear. The modiolus and whole internal ear should be broken down, and this communicating path between the internal auditory meatus and the middle ear should be made as large as possible. When the modiolus is broken down and the internal auditory meatus opened there will be an escape of cerebrospinal fluid; the passage must then be packed tightly.

4. The bridge of bone now remaining between Trautman's triangle posteriorly and the middle ear, which holds the facial nerve and the semicircular canals, should be broken down and absolutely destroyed. The brain will thus be exposed over an area extending from the carotid artery in front to beyond the sinus behind, and the area of dura in the region of the internal auditory meatus has a straight passage for draining to the outside.

Layman reports a cure of a case of purulent leptomeningitis of otitic origin, in which the Crockett technic was employed. This method, to which the author ascribes his first cure of diffuse purulent meningitis, consisted in making a one and one-half inch opening of the dura at the bottom of the bone opening and inserting subtemporal drains along the top of the petrous portion of the temporal bone.

Page reports the case of a boy, ten years of age, on whom a simple mastoid operation was performed, and three days later there began to develop a facial paralysis which was complete in two days. Two days later there occurred suddenly, with vomiting and tinnitus, but apparently without nystagmus or vertigo, total loss of hearing in the opposite ear, and it was then noticed positively for the first time that there was almost total loss of hearing on the operated side. A high leucocyte count and cloudy cerebrospinal fluid were present.

The interesting point in this case is the cause of the deafness. The sudden loss of hearing with roaring tinnitus and vomiting would first of all point to the labyrinth, but because of the fact that from first to last the patient was at all times able to sit up without disturbance of equilibrium, speaks 
against this view. The conclusion reached was that meningitis was the cause of the persistent vomiting and deafness, and that the invasion of the meninges very likely took place along the route of the facial nerve.

Perkins discusses the value of leucocytes of the spinal fluid in the diagnosis of meningitis and wisely places this where it belongs, namely, as an aid to clinical observation. When thus considered, he regards the cell count of the spinal fluid, with the determination of the polymorphonuclear percentage, as one of the most important laboratory aids in the diagnosis and management of meningitis. $\mathrm{He}$ warns that one should always be on the lookout for other diseases, which give leucocytosis of the spinal fluid, especially syphilis in its various forms, because the most that can be interpreted from the presence of an increased leucocyte count with a substantial polymorphonuclear percentage, is that an inflammation exists either within the meninges themselves or in their immediate proximity. The deciding factors are the clinical phenomena.

Perkins reports a case of meningitis following a suppurative labyrinthitis, which passed into the latent stage and was associated with facial paralysis. For three days there was a clinical picture of meningitis, but spinal fluid examination revealed but 15 cells to the $\mathrm{m}$. $\mathrm{m}$. Twelve of these, or 80 per cent, were polymorphonuclear. Operation was deferred because of the small number of cells, but in commenting on the case the author thinks he should have operated because of the clinical symptoms and the high polymorphonuclear percentage. Twenty hours later the laboratory reported 512 cells to the m. m., and operation was performed, at which time a labyrinthectomy with cerebellar and subtemporal decompression was done.

Two days after the operation the brain was sloughing and foul smelling. Dakin's solution was used with marvelous effect, the brain became firm and healthy, and dermatized over. The patient died in a comatose condition about three and one-half months later, the exact cause of death being obscüre. The spinal fluid remained clear throughout, consequently the author feels that death did not result from a reinfection of the meninges. Operation and autopsy were refused. 
MiscELLANEOUS.-Boot describes the following cases:

1. Acute mastoiditis with operation and recovery, followed in three months by severe headache and dizziness with vomiting. Operation disclosed an extradural abscess, after which patient recovered.

2. Chronic suppurative otitis media on left side, with temporosphenoidal abscess in a boy fourteen years old, in whom the important symptom was the loss of power to name objects. Operation was successful.

3. Chronic suppurative otitis media on left side with subperiosteal abscess in front of the auricle, extradural abscess and temporosphenoidal abscess. Operation succeeded in evacuating the pus, but patient died suddenly after nine days. The loss of power of naming objects was.demonstrated in the case. Streptococcus hemolyticus was recovered from the abscess cavity at postmortem examination.

4. Chronic suppurative otitis media on the left side, cholesteatoma, mastoiditis, labyrinthitis, dehiscence of tegmen tympani, abscess of temporosphenoidal lobe, meningeal hemorrhage and jaundice. In this case the temporosphenoidal lobe was explored with a large needle, but no pus found. At autopsy the abscess cavity was found to have been punctured by the exploring needle, from which fact the author concludes that it is a mistake to use a needle for exploring the brain. This patient also had a loss of memory for words.

5. Acute suppurative otitis media, mastoiditis, sinus thrombosis, abscess of temporosphenoidal lobe, meningitis, operation and death five days later.

6. Chronic suppurative otitis media on the left side, aural polyp, cholesteatoma, facial paralysis, fistula of external semicircular canal, meningitis. Operation performed and patient doing well two weeks later when report was made. In this case the function of the left vestibular system was interfered with, as shown by nystagmus to the right, but not abolished, as shown by the fact that the nystagmus to the right was reversed when the left ear was irrigated with hot water.

7. Chronic suppurative otitis media, with cerebellar abscess, meningitis and death. The marked symptoms were the severe headache, the unsteadiness of gait and the pain the back. 
The abscess, discovered at the autopsy, lay over the saccus endolymphaticus.

8. Syphilitic meningitis, total labyrinthine deafness in one ear and nearly total labyrinthine deafness in the other ear. After intensive antiluetic treatment, patient had total recovery of hearing. The severe headache was most troublesome.

9. Fracture of skull with bilateral labyrinthine deafness.

10. Chronic suppurative otitis media with cholesteatoma, mastoiditis, sinus thrombosis, slough of sinus wall, embolic pneumonia, hernia cerebelli, facial paralysis, operation and recovery.

11. Bilateral mastoiditis, with thrombosis of the superior longitudinal sinus and jaundice. The thrombosis of the sinus was discovered at autopsy. The important symptoms noted were: (a) General interference with mental processes, explainable by the disturbed nutrition of the cortex; (b) nose bleed, probably due to venous stasis in the upper part of the nose, and (c) jaundice, probably of bacteremic origin.

12. Acute suppurative otitis media, labyrinthitis. anomalous pointing reactions, and facial paralysis. Recovery.

The anomalous pointing reactions which were past-pointing to the left with the right hand no past-pointing with the left hand, in association with spontaneous nystagmus to the right due to left labyrinthitis, are explained in two days: There was either a cerebellar lesion that suspended the action of the centers for outward deviation of the left hand or a hyperirritability of the center for inward deviation of the left hand. Because of the favorable outcome, the author favors the latter hypothesis.

The conclusions offered by the author from a study of these cases are:

1. The diagnosis of these complications is not easy, but requires careful examination of the history, the symptoms, the functional tests and the laboratory findings.

2. In extradural abscess the most characteristic symptom is the severe one sided headache, in a patient who has or who has had a running ear.

3. In abscess of the left temporosphenoidal lobe the most characteristic symptom is the loss of memory for names, with 
weakness of the facial muscles on the right side. If the abscess is in the right temporosphenoidal lobe, memory for names is not lost unless the patient is left handed, in which case it might be lost. Right sided facial paralysis may be present.

4. If the patient has a labyrinthitis, complete labyrinthine deafness, anomalous pointing reactions, headache, choked disc, look out for cerebellar abscess, and when exploring for it, remember that the abscess is apt to lie either near the internal meatus or over the saccus endolymphaticus.

5. If the patient has rigid neck, positive Kernig and a cloudy cerebrospinal fluid with increased polynuclear count, the diagnosis of purulent meningitis is settled.

6. In the cases of thrombosis of the superior longitudinal sinus there is a lack of mental ability, an inability to comprehend what is said and to reply, that is quite characteristic when once seen but which is difficult to describe. Nose bleed is a symptom of considerable importance in the diagnosis of this complication.

7. Syphilis of the vessels, syphilitic meningitis and gumma usually lack the preceding middle ear suppuration. The symptoms are not apt to be confined to one side of the head, and the Wassermann on the blood and cerebrospinal fluid gives an indication of the cause of the symptoms.

8. When in doubt it is probably better to explore the brain, best done by means of the double bladed explorer, similar to the one devised by Gifford of Omaha.

Hastings reports two ear cases with intracranial complications. The first one was a honeycombed caries of the petrous bone, secondary to chronic middle ear suppuration, causing meningitis and death. At autopsy the condition was discovered only after stripping the dura from the petrous bone. In this case the petrous pyramid was unusually cellular, thus accounting for the spread of the suppuration in this direction. The second case was one of temporosphenoidal abscess secondary to chronic middle ear suppuration, successfully operated eight years ago. There was a recent attack of dizziness; demonstration of fistula in the horizontal semicircular canal; reoperation; caries of labyrinthine walls found; recovery after a radical mastoid operation. 


\section{VII.-Disenses of the INTERNaI, EAr.}

1. Gluck, Charles.-Common Deafness: Its More Accurate Handling. Med. Rec., N. Y., 1918, XCIII, 410.

2. Mackenzie, G. W.-Syphilis of the Inner Ear and Eighth Nerve. Am. J. of Syph., 1918, II, 241.

3. Mackenzie, G. W.-The Report of a Case of Neuritis of the Eighth Nerve Involving Both Branches, from a Focal Infection in the Appendix. Ann. Otol., Rhinol. \& Laryngol., St. Louis, 1918, XXVII, 490

4. Mygind, S. H.-A New Symptom of Labyrinth Fistula. J. Laryngol, Lond., 1918, XXXIII, 143.

Rott, O. M.-The Clinical Interpretation of Labyrinthine Phenomena in the Presence of Suppurative Inflammation of the Middle Ear. Northwest Med., Seattle, February, 1918.

Gluck divides nerve deafness into two types:

1. Disease of the vestibule or cochlea, which is actually disease of the auditory nerve filaments or endings.

2. Disease of the auditory nerve itself, or auditory brain centers or both.

The former, the most common, is due to involvement of these structures by extension of similar inflammatory processes working through the middle ear and is to be treated by attention to the abnormal conditions in the nose and throat.

The latter, the rare type, is caused by disease gaining entrance through the blood.

Mackenzie offers a contribution to the subject of syphilis of the inner ear and eighth nerve. The points of chief interest to which the author draws attention are:

1. That syphilitic changes in the inner ear are due to extension from either the nerve on the one side or the middle ear on the other.

2. From our present knowledge, we may accept (a) primary atrophy of the eighth as well as the second nerve as an accompanying manifestation of parasyphilis; (b) primary atróphy is produced by a pre-existing low grade syphilitic meningitis; (c) eventually the pia mater contracts and squeezes the life out of the nerve.

3. In those cases where the syphilitic meningitis is more pronounced the inflammation spreads to and involves the nerve, so that the clinical evidence of neuritis manifests itself simultaneously with or shortly following the meningitis. At 
a later period the connective tissue elements in the nerve may contract and produce secondary atrophy.

4. Bilateral diminution or complete loss of hearing, when found to be due to a lesion of the perceiving apparatus as determined by carefully conducted functional fork tests, speaks decidedly for the diagnosis of syphilis.

5. Bilateral diminution or loss of the socalled turning, caloric and galvanic tests likewise speaks for syphilis.

6. Bilateral diminution or complete loss of hearing function from a lesion in the perceiving apparatus combined with bilateral diminution or loss of vestibular function speaks for syphilis.

7. Pronounced loss of either function on one side with but moderate diminution of function on the other speaks equally strong for syphilis.

Mackenzie reports an interesting case of neuritis of the eighth nerve which was due to a focal infection in the appendix.

Mygind describes a new symptom of labyrinth fistula which consists in a nystagmus to the healthy side when the carotid of the diseased side is compressed, followed in a short time by cessation of the nystagmus, and finally a nystagmus to the diseased side when pressure on the carotid is released. This symptom has been observed in four cases.

Rott emphasizes that when spontaneous labyrinthine phenomena occur in the course of suppurative inflammation of the middle ear, the decision concerning the advisability of a mastoid operation rests largely on the question as to whether the type is a paralabyrinthinitis or an acute diffuse labyrinthitis, and, if the latter, whether there are or are not symptoms of meningeal involvement. If, for instance, during the course of a suppurative inflammation of the middle ear, the patient should complain of vertigo, nausea and vomiting, and an examination of the eyes revealed the presence of a nystagmus (that is, the quick component) toward the diseased ear, with deafness not absolute, the condition would be a paralabyrinthitis and the best treatment would be the prompt opening of the mastoid.

If, on the other hand, there was absolute deafness of the suppurating ear, with the nystagmus directed toward.the well 
ear, the condition would be one of diffuse labyrinthitis, and the best interests of the patient would be served if we refrain from opening the mastoid during the acute stage, unless there are unmistakable evidences of beginning meningeal involvement, as determined by a temperature of over $100^{\circ}$, headache, photophobia, exaggerated reflexes, a positive Kernig, and positive findings in the cerebrospinal fluid.

Before undertaking a mastoid operation in chronic suppurative otitis media, the labyrinth should be tested, and if found nonfunctionating, it would be safer to follow the mastoid operation immediately by a labyrinthine exenteration rather than to perform the mastoid operation alone.

$$
\text { VIII.-INJURIES. }
$$

1. Jones-Phillipson, C. E.-War Injuries and Neuroses of Otological Interest. J. Laryngol., Lond., 1918, XXXIII, 77 and 111.

2. McBride, P., and Turner, A. L.-War Deafness, with Special Reference to the Value of the Vestibular Tests. Lancet, London. 1918, CXCV, 73.

3. Richardson, C. W.-Ear Protectors. Laryngoscope, St. Lou1s, 1918, XXVIII, 514.

4. Wilson, J. Gordon.-The Effect of High Explosives on the Ear. N. York M. J., 1918, CVII, 357.

Jones-Phillipson has analyzed 100 cases of war injuries to the ear.

There were thirty-one cases of laceration of the membrana tympani. Various degrees of laceration of the external ear were commonly seen-slits, perforations or nearly complete severance of the auricle. They healed well and quickly. 'Two cases of severe perichondritis of the auricle with abscess formation were seen. There were four cases of firm blood clot in the middle ear, bulging the membrane outwards. An analysis'of the symptoms, presented in order of frequency are:

1. Deafness, increased deafness, "dullness in ears."

2. Noises in great variety (singing, buzzing, hissing, straining, thumping, bells, throbbing, ticking).

3. Giddiness, dizziness, "dazed."

4. Pain, soon passing off.

5. Bleeding, at the time, or noticed soon after.

6. Staggering gait, inability to walk, unconscious, dumbness, blindness. 
Analyzing shell concussion effects on the internal ear, the author observes that the membrana tympani is of much greater area than that of the fenestra valis. The ossicles convey vibrations from the large area to the small; much greater force must therefore be applied to the small area. Different effects on the internal ear are to be expected if the full force has been transmitted to the fenestra valis, the membrana tympani having withstood the force of the concussion, and a less effect if the membrana tympani has been lacerated, much of the force being lost; and in cases of otitis media suppurativa with large losses, where the remains of the membrana tympani and the diseased condition of the contents of the middle ear have been much minimized in value as transmitters.

Shell concussion deafness is probably due to three contributory factors:

1. Cerebral concussion.

2. Overstrain and fatigue of the organ of Corti; the former being due to violent oscillations of the perilymph communicated to the organ of Corti, and the latter to continuous violent noises or explosions at close quarters.

3. Temporary or permanent disorganization of the conductive apparatus.

The prognosis depends on the recovery of these parts.

1. The patient experienced a great shock, and was, in many instances, buried. He became suddenly deaf, and often dumb also. In other cases he could not see, or had paresis of arm, leg, or both legs. Here the higher centers were temporarily involved. One watched the almost sudden improvement in hearing in a few days as shock passed off, and the disappearance of nervous symptoms generally when the patient was removed from the firing line.

2. A portion of deafness remains to be more or less slowly recovered from by the return of the internal ear to a normal or nearly normal condition.

3. Structural damage must leave a permanent imperfection of function-a ruptured membrane, a dislocation, partial or complete, of the small bones from one another, or the stretching of their attachments to the tympanic wall.

McBride and Turner have reached the following conclusions concerning war deafness and the value of the vestibular tests: 
1. That concussion deafness is generally due to some organic change.

2. That the prognosis is usually bad.

3. That the results of the vestibular tests can only be utilized in conjunction with information derived from other sources. Thus, if the patient shows other hysterical symptoms vestibular tests may perhaps under certain circumstances help diagnosis; but to state that they do more than this is misleading and dangerous.

With a view to determining the relative merits of the various ear protectors against concussion deafness, Richardson has had experiments made on animals, from which he has deduced the following conclusions:

1. Of the four protectors tested (British Tommy, MallockArmstrong, Baum, and Wilson Michelson), the British Tommy is the best.

2. Cotton is efficient only when moistened with glycerin or vaselin. It deafens the wearer more than the Tommy.

3 . It is recommended that several thousand Tommy protectors be purchased and issued to the troops with orders to wear them the same as their gas masks.

4. It is recommended also that cotton saturated with glycerin and vaselin be issued to a certain number of men, so that the relative merits of the Tommy and vaselin cotton can be determined.

Wilson discusses the effect of high explosives on the ear and divides the cases of deafness due to war conditions into two classes, one including all cases in which there had been a direct wound of the ear by a missile and the other including those injured by the effects of an explosion without direct wound of the ear. It is the latter class alone which the author considers. These cases had been termed shell shock deafness, and there had been a great tendency to associate the condition with hysteria and neurasthenia, but the author advises the avoidance of these terms as confusing. .

The effect of a high explosive was a great and sudden compression followed by an equally great and sudden decompression. This compression and decompression could amount to 10,000 kilograms a square meter. The author referred to the fact that there were certain normal limits to the capacity of 
the auditory apparatus to withstand pressure changes, and that pressures beyond the normal caused disturbances of hearing such as hyperacusis, hypoacusis, or total deafness.

The men with symptoms of nerve deafness due to the effects of high explosives could be classified as those with true nerve deafness; those who had had nerve deafness and who retained the fixed idea that they could not hear: and those who were malingering. The first class alone is discussed, and in this class there are three groups of cases.

(a) In the first group, the nerve deafness was associated with damage to the conducting mechanism, such as perforation of the tympanic membrane, hemorrhage into the middle ear, or infection of the middle ear.

(b) The second group comprised those cases in which there was no demonstrable lesion in the conducting mechanism.

(c) The third group was composed of those cases in which there was destruction of the cochlea and semicircular canals or their nerves.

The deafness might be partial or total in either of the first two groups, but was always total in the third. The symptoms of all three groups fell within the description of traumatic neuroses, and most of the patients exhibited variable and complex symptoms aside from deafness. Such symptoms included the various common manifestations usually associated with neurasthenia or hysteria.

The author pointed out that in those cases where there were no evidences of structural injury there still might be some microscopic damage to the structures of the internal ear. In this connection the author reported on two specimens, secured within six hours after death. in which it was known that the patient had sustained the effects of high explosives and developed nerve deafness. The microscopic examination revealed lesions confined to the cochlear structures, closely resembling the experimental lesions made on animals by pistol shots. The membrana tentoria was found swung up against Reissner's membrane and was attached to it by a serous and cellular exudate. The organ of Corti showed marked swelling of the cells, and microscopic hemorrhages were found in the internal ear alone, with evidences of an acute neuritis of the eighth nerve. No hemorrhages were found in Corti's organ. 
With these lesions it was found that the stapes was intact and the vestibule had not been injured.

Concerning the methods employed for improving the hearing, the best results were obtained by stimulating the nerves by means of the voice and tuning forks through resonators. Electricity was harmful. No results were obtained where the internal ear was destroyed.

As a preventive measure the author recommends the WilsonMichelson hard rubber device, which permitted the hearing of all normal sounds, but which also closed tightly in response to loud noises and protected the ear against injury by detonations. This device was smaller than the Malloch-Armstrong protector and did not irritate the canal or cause any discomfort to the wearer. Cotton plugs and wax or cotton impregnated with petrolatum were condemned.

$$
\text { IX.-Education of the Deaf. }
$$

1. Blake, C. J.-Speech Reading for the War Deaf. Boston M. \& S. J., 1918, CLXXIX, 697.

2. Morgenstern, Louise I.-The Medical Profession and the Dear. Laryngoscope, St. Louis, 1918, XXVIII, 612.

3. Scripture, Mrs. May K.-Abnormal Voices: Falsetto, Nasality, Hoarseness, Cleft Palate Speech, Choreatic Speech, Anarthria, the Voice of the Deaf, and the Mental Deflcient. Laryngoscope, st. Louis, 1918, XXVIII, 457.

Blake presents an interesting discussion of speech reading for the war deaf, emphasizing the place it should occupy in the rehabilitation of the deaf soldier and sailor. Granting that instruction in speech reading should be under the direction and control, firstly, of the General Medical Staff, and secondly, of the medical staff of the hospital or other institution in which the teaching is applied, Blake asserts that this teaching, in order to achieve its highest physiologic, as well as its most immediate practical value, should stand in a class by itself like the vocational training; not a part of the hospital treatment of the disorder from which the patient is recovering, but the first step toward the resumption of the individual place in civil life.

This educative rehabilitation which, while it may begin in the hospital ward, is distinctly a pedagogic process and should 
be mentally differentiated as such, since, when so regarded, it becomes a stimulus to the effort to get into the competitive activities of existence again.

Miss Morgenstern points out the invaluable aid of lip reading to the deaf, not only in teaching the deaf to understand what cannot be heard, but also in reconstructing the entire mental life and habits.

The medical profession as a whole is taken to task for the half hearted interest displayed and the perfunctory advice given to their deaf patients, and a plea is made for closer cooperation between the physician and those giving their time to the work.

Mrs. Scripture lays down the following lines along which speech development in the deafmute should proceed:

1. Breathing through the nose and mouth are first taught. The teacher breathes through the nose on a slate or a mirror and shows the two moist spots; the child learns to imitate this. The mouth breathing produces one spot.

2. The low position of the tongue is necessary for proper speech. It is taught by showing the position and using the mirror, and by breath exercise. This latter rests upon the fact that the child cannot produce a good sized spot on the slate unless he keeps his tongue down.

3. Tongue gymnastics are next used to limber up and train the muscles which have never received the proper development. The tongue is protruded, retracted, moved to each side, turned up, etc.

4. Tongue training preparatory to various consonant sounds is introduced. For example, the child is taught to put the tip of the tongue against the upper teeth; this gets him ready for the letter "t." He learns to draw it back and close it against the hard palate, thus getting ready for " $k$."

5. Vibration of the vocal cords is taught by feeling. The pupil puts his hand on the teacher's chest and also on his own. He thus learns to make a tone. He learns to raise the voice, and by careful drill is able to make a fairly good tone.

6. The physiologic alphabet consists of a set of diagrams giving the typical position of the tongue and lips for the chief sounds of the language. 
7. Combinations of consonants and vowels are now read at sight. Through these combinations words and sentences are developed.

8. Lip reading of words and sentences are taught by having the patient watch the teacher's lips while she distinctly enunciates some word. Thus he learns to pick up objects off the table, etc.

\section{X-Misceili,anedous Topics.}

1. Davis, G. E.-The Importance of Recognizing the Relation of Ear Conditions to the General System. Ann. Otol., Rhinol. \& Laryngol., 'St. Louis, 1918, XXVII, 226.

2. Harris, T. J.-Radium in Diseases of the Ear. Ann. Otol., Rhinol. \& Laryngol., St. Louis,'1918, XXVII, 986.

3. Kobler, E. Willis.-A Survey of Ear Conditions in School Children. N. York M. J., 1918, CVIII, 66.

Davis reports three cases of aural symptoms, in which a complete functional examination disclosed the absence of any local trouble, but in which the general system was at fault. In two cases a general syphilitic infection gave rise to the aural complaint because of neuritis of the eighth nerve. In the other case vertigo was due to thyroid trouble.

Harris reviews the literature on the influence of radium in diseases of the ear, and offers the following conclusions:

"Radium up to the present time has failed to be of any considerable benefit in the treatment of diseases of the ear. So far as chronic deafness is concerned, it has proved virtually a failure. In the rare cases of intractable tinnitus and excessive vertigo, on the other hand, it can be employed with a reasonable hope of relief by its power of destroying the labyrinth. Finally, so far as malignant growths are concerned, it is of value when they are superficially seated. When deep seated, there is nothing sufficiently encouraging to be said of it to warrant its use to the exclusion of operative measures where they can with propriety be adopted. The work that has already been done with it on the ear is not enough to condemn it "in toto," however, and it is to be hoped that other investigators will take it up and give it further thorough and careful trial.

Kobler has examined the ears of 500 school children and found that 64 gave a history of some previous ear discharge; 
9 had skin lesions, malformations, etc., of the external auditory canal and adjacent structures; 152 showed relative degrees of impairment of hearing; 285 had cerumen in relative degree of excess over normal; 8 had a present ear discharge and 59 exhibited marked associated defects bearing relatively upon the condition of hearing. 404 Paulsen Building. 